This paper was presented in its original form at Seminars held in Auckland, Canterbury and Victoria Universities during 1975 to provide background information for NZS 4203 .

\title{
DESIGN OF SHEAR WALLS FOR SEISMIC RESISTANCE
}

\author{
I. C. Armstrong*
}

\begin{abstract}
Ductile coupled shear walls, ductile cantilever shear walls, and less ductile "category 6" shear walls comprise three basic shear wall types included in categories $3,4,5$ and 6 of Table 5 of the earthquake provisions of the New Zealand Loadings Code. Seismic resistance of these shear wall types, when fully cracked with reinforcement at or near yield where applicable, is discussed relative to code provisions. Reinforcement requirements are outlined, using capacity design criteria for ductile walls, and load-factor methods for "category 6" shear walls requiring distributed vertical and horizontal reinforcement to control cracking.
\end{abstract}

\section{INTRODUCTION}

Design for ductility, inelastic dissipation of seismic energy, and acceptable post-cracking behaviour of the main lateral load resisting elements of building structures is a basic objective of the earthquake provisions, part 3 of the New Zealand Loadings Code(1). Shear walls coming within categories $3,4,5$ and 6 of Table 5 of the code are required to be designed and detailed to dissipate seismic energy in the manner envisaged while preventing premature, nonductile failure mechanisms (e.g. premature or uncontrolled shear, anchorage, instability).

In prescribing design principles for shear walls, clause 3.3 .4 indicates three basic shear wall types, having quite different characteristic modes of behaviour when resisting earthquake attack, for which differing values of structural type factor $S$ are specified in Table 5 of the code:

(1) cantilever shear walls designed for ductile flexural yielding (categories $4,5)$

(2) shear walls not designed for ductile flexural yielding but having the ability to dissipate a significant amount of seismic energy by other processes (category 6).

(3) coupled cantilever shear walls designed for ductile flexural yielding (category 3).

This paper considers seismic resistance of the three shear wall types when fully cracked, with reinforcement at or near yield where applicable, and aims to elucidate aspects of behaviour envisaged by the code provisions. Reinforcement requirements are outlined, using capacity design criteria for ductile walls at overstrength capacity or load-factor design methods for less ductile shear walls resisting code seismic loads. Additional detailing aspects are listed in an appendix.

Design should also consider foundation stability in resisting overturning due to seismic loads or at overstrength capacity when ductile hinge mechanisms have developed,

* District Structural Engineer, Ministry of Works and Development, Auckland. to preclude premature rocking, uplift or failure of the foundation system. Concurrency effects should be considered where applicable. If rocking occurs at a lower lateral load, energy dissipation could be drastically reduced since the intended mechanisms may be prevented from functioning, and considerable damage or failure may result. Discussion of this important design aspect is not, however, included in the paper.

\section{TALL, DUCTILE, CANTILEVER SHEAR WALLS}

Cantilever shear walls designed and detailed for ductile flexural yielding (clause 3.3.4.2 and commentary) comprise categories 4,5 of Table 5 of the code. Structural type factors are $S=1.0$ for two or more such walls approximately symmetrically arranged (category 4 ) and $S=1.2$ for single ductile cantilever shear walls (category 5). These walls are required to have a ratio of total height $h_{W}$ to horizontal length $l_{W}$ not less than 2 , and also to have a horizontal length (described alternatively as width or structural depth, D) not less than 1.5 metres. Openings shall be such as not to have a significant effect on the behaviour of the wall under earthquake attack.

Tall, ductile cantilever shear walls dissipate seismic energy by plastic flexural hinging of the full wall section, usually at the base, with tension steel yielding across flexural cracks opening in the hinge zone. Behaviour is characterised by flexure, in combination with relatively small axial loads, as for ordinary reinforced concrete members of normal proportions; basically, they are flexural cantilevers rather than "shear" walls.

In this type of member diagonal cracks would be expected to be flexure-shear cracks (i.e. initiated as a flexural crack and subsequently extended diagonally as a shear crack). Critical diagonal cracking would therefore occur at lower or intermediate heights in the wall and especially in association with near-maximum moment effects (fig. 1), but diagonal cracking at relatively high levels (i.e. intersecting the main flexural reinforcement near the top of the wall) is unlikely to be critical or affect 
performance where $h_{\mathrm{W}} / l_{\mathrm{W}}$ exceeds 2 . For equilibrium of the free-body element (fig. $1)$, the shear force $V$ is transferred across the diagonal crack by horizontal stirrups while the flexural tension force $T$ resists overturning of the wall element and controls crack width. Since each such critical diagonal crack (idealised) intersects and is stabilised by the main flexural steel in the tension flange area, it follows that vertical reinforcement in the web area is not required for equilibrium of the wall element. However, some vertical web steel may be provided for other reasons (shown dotted in fig. 1).

The code intent is that category 4,5 walls should behave as ductile flexural members subject to relatively small axial loads. They should be detailed for ductility, and capacity design methods should be used where applicable (e.g. design of shear reinforcement and of the foundation structure and system). The risk of non-ductile behaviour increases for wall sections carrying high axial or shear stresses, or which contain high percentages or unsymmetrical arrangements of main reinforcement. In the interim untii the materials code committee sets specific, detailed design criteria, some guidance can be obtained from the loadings code commentary, published research $(3,4)$, and existing design codes. Applicable requirements would include the following:

(a) reasonably symmetrical arrangement of main reinforcement (commentary clause C.3.3.4.2.1).

(b) nominal shear stress on the wall section at hinging capacity should not exceed $0.5 \sqrt{\mathrm{f}_{\mathrm{C}}^{\prime}} \mathrm{MPa}\left(6 \sqrt{\mathrm{f}_{\mathrm{C}}^{!}} \mathrm{psi}\right.$ ) (ref. 4$)$.

(c) minimum areas of distributed horizontal and vertical reinforcement (ACI Code $(2)$ Cl.A.8.2).

(d) minimum area of vertical reinforcement concentrated near the ends of the wall (ACI Code, Cl.A.8.4).

(e) reinforcement ratio of tension reinforcement, $p$, should not exceed 0.50 of the ratio producing balanced conditions, i.e. simultaneous assumed ultimate strain of concrete and yielding of tension steel (ACI Code, C1.A.5.1).

(f) maximum design axial load acting on the wall during earthquake, $\mathrm{P}_{e}$, should not exceed $0.4 \mathrm{~Pb}$, where $\mathrm{Pb}_{\mathrm{b}}$ is the axial load capacity of the wall section at balanced conditions (ACI Code, Cl.A.6.3, A. 8).

\subsection{Design for Flexure and Axial Load}

For vertical steel percentages appreciably greater than the minimum, wall section ductility is markedly reduced where main flexural steel is distributed over the whole section depth. Therefore, nearly all the main vertical bars resisting moment and axial load should be positioned close to the extremities of the wall section, or in the flanges. This arrangement uses the steel most efficiently, and also provides suitable amounts of steel in the compression zone; thus, the external moment is resisted mainly as a steel couple, and the concrete compression area depends upon the magnitude of the gravity axial load.

In the web, some vertical steel (minimum $0.25 \%$ ) should be provided for crack control.
This may be increased if necessary to assist transfer of web shear forces across construction joints by aggregate interlock (shear-friction). A complication can arise in practice where the web being considered may constitute a flange in the other horizontal direction, and thus it contains a substantial quantity of main vertical bars.

Flexural reinforcement requirements are calculated using specified gravity and seismic lateral load combinations and capacity reduction factors. Where gravity loads are small the calculation of flexural steel areas can neglect axial force as in a reinforced concrete beam. Larger axial loads necessitate the use of axial load/moment interaction curves computed for trial arrangements of vertical bars in the section. For unsymmetrical, flanged sections these curves are different for each direction of moment and load.

Ductility of the critical hinge region is improved by special detailing to confine compression zones similarly to columns, with transverse ties closely spaced round vertical bars in the compression zone. Spacing of these ties should not exceed 6 times the main bar diameter, to avoid buckling of the main bar when it is at yield in compression. These measures are especially necessary in the hinge region of rectangular wall sections, and where the section carries considerable gravity loads which reduce available ductility.

\subsection{Overstrength Moment Capacity of Wall \\ Hinge}

When actual sizes, numbers and steel grade of all vertical bars have been selected, the overstrength hinge moment capacity of the full wall section is calculated considering all vertical bars in web and flanges. The effect of axial load in increasing moment capacity should be included, and thus the load combination given by eq. 4 of the Loadings code $\left(U=1.0 D+1.3 L_{R}+E\right)$ is usually the governing condition for capacity assessment. The calculation of moment capacity should allow for all likely sources of overstrength (e.g. higher yield strength and strain hardening of the actual bars in the structure, for which a steel stress not less than $350 \mathrm{MPa}$ is suggested in appendix I). A capacity reduction factor $\phi=1$ is used with accepted methods of capacity design.

Where there is a lack of symmetry in either wall section geometry or arrangement of reinforcement, overstrength hinge moment capacity should be calculated in each direction of moment. In cases where the web contains main bars relative to its function as a flange in the other horizontal direction, significantly increased moment capacity may be unavoidable.

\subsection{Design for Shear}

To prevent premature, non-ductile shear failure, the shear forces to be resisted throughout the wall height are those associated with the development of full moment capacity at the hinging region (usually at the base of the wall). These hinge capacity shear forces and the diagram 
showing their distribution over the wall height are calculated from the base hinge moment capacity assuming a triangular (i.e. code) loading distribution pattern as used when determining design moments. This shear force diagram should be increased in magnitude by a factor (described in the following paragraph) to determine shear forces for design of shear steel. The code commentary (C.2.3.3.2) refers to the effect of dynamic response in higher modes, which may cause the resultant inertial horizontal force to act at a lower (or sometimes higher) height than given by the triangular code loading pattern. Thus, for short but significant periods of time, considerably increased shear forces may act on the wall to develop its hinge moment capacity. Based on a recent study (5), the commentary recommends values of the factor to be applied to the hinge capacity shear force diagram. This factored shear force diagram is used for design of horizontal shear reinforcement.

Normal design methods should be used in calculating the horizontal reinforcement required to resist shear $(\phi=0.85$; specified minimum $\left.f_{Y}\right)$. Where vertical reinforcement yielas in the hinge zone, horizontal shear steel should be provided to resist the full design shear force, neglecting contribution of the cracked concrete. This applies over the full plastic length, i.e. over a height of wall not less than the horizontal wall length $1_{\mathrm{W}}$. Above this level, contribution of the concrete to shear strength may be taken at a nominal shear stress of $0.16 \sqrt{f_{\mathrm{C}}^{\prime}} \mathrm{MPa}\left(2 \sqrt{\mathrm{f}_{\mathrm{C}}^{\prime}} \mathrm{psi}\right)$.

At horizontal construction joints in shear walls, shear is transferred by aggregate interlock (shear-friction). To provide the necessary clamping forces preventing separation of the joint surfaces, distributed vertical web reinforcement at relatively close spacing crossing the construction joint is required, otherwise a sliding shear failure could occur. Paulay has provided design guidance(1), and recommends that a friction factor of unity be taken in the calculation of vertical web reinforcement. This web steel should be sufficient to transfer the full design shear force (i.e. the factored shear force diagram) used for design of horizontal shear reinforcement. Paulay recommends that the average ultimate shear stress transferable across a well prepared rough construction joint, $v_{u f}$, be calculated by the following formula (1):

$$
v_{u f}=\left(A_{v f} f_{y}+N\right) / A_{g}=p_{v} f_{y}+N / A_{g}
$$

where $A_{v f}=$ total distributed vertical steel to be utilised for the required clamping force.

$\mathrm{A}_{\mathrm{g}}=$ gross area of a rectangular shear wall section.

$\mathrm{N}$ = axial force on the section taken as positive when producing compression.

$f_{y}=$ the yield strength of the reinforcement used.

$\mathrm{p}_{\mathrm{V}}=$ reinforcing steel content.

\section{CATEGORY 6 SHEAR WALLS}

Shear walls not classified as either ductile cantilever or ductile coupled shear walls are presumably considered as being not able reliably to dissipate adequate amounts of seismic energy by ductile flexural yielding, and thus a higher structural type factor applies. Clause 3.3.4.3 and category 6 of Table 5 specify a factor $S=1.6$ for shear walls of horizontal length (width) $I_{W}$ not less than 1.5 metres which are not designed for ductile flexural yielding but through suitable design and detailing have the ability to dissipate a significant amount of seismic energy by other processes.

These other processes would include those associated with less ductile behaviour in flexure, for example, in over-reinforced wall sections requiring special confining reinforcement for core areas of compression zones subject to large compressive strains and spalling of cover concrete. Processes associated with "Controlled shear" behaviour are also included, and suitable detailing for this is required in category 6 walls having a total height $h_{\mathrm{w}}$ to horizontal length $1_{w}$ ratio of 2 or less. Controlled shear behaviour applies where the formation of a system of distributed cracks (mainly diagonal) and subsequent behaviour is controlled by adequate vertical and horizontal reinforcement in web areas so as to prevent premature failure in shear.

Category 6 shear walls required to be detailed for controlled shear (distributed diagonal cracking) behaviour comprise two dimensionally different groups exhibiting significant differences in cracking and behaviour. These are considered separately in subsequent sections, and summarised here:

(a) Low shear walls $\left(\mathrm{h}_{\mathrm{w}} / 1_{\mathrm{w}}<1\right)$

With or without actual flanges, these walls are characterised by web-shear diagonal cracking (fig. 3). Due to web dimensions, crack patterns and mechanisms of shear transference, the terms flexure and ultimate flexural capacity appear to have little meaning.

(b) Intermediate shear walls ( $1 \leqslant \mathrm{~h}_{\mathrm{w}} / 1_{\mathrm{w}} \leqslant$

This group includes square shaped walls and also those of intermediate height up to $h_{\mathrm{W}} / l_{\mathrm{W}}=2$ (fig. 2 ). When heavy flange reinforcement or other conditions (e.g. foundation stability) preclude the attainment of theoretical flexural strength, diagonal web cracking dominates behaviour. In cases where yielding of tension reinforcement is attainable, behaviour may be an intermediate condition due to a combination of yielding across flexural cracks and diagonal web cracking.

Where diagonal cracking behaviour is significant, it is assumed herein that horizontal web reinforcement is effective in transferring shear forces provided it is designed to resist the full ultimate shear load crossing the diagonal crack. No reliance is placed upon any contribution to shear strength by concrete mechanisms, e.g. aggregate interlock. This applies to category 6 shear walls of $h_{\mathrm{W}} / l_{\mathrm{W}} \leqslant 2$ i.e. in low and intermediate shear walls. This assumption is made because diagonal cracking of these walls causes mainly shear deformation, producing separation of the crack surfaces in the direction of the shear force $(6)$ so 
that as the crack opens aggregate interlock may reduce drastically or become ineffective. In contrast with this situation, flexural members of normal proportions subject to flexure-shear diagonal cracking sustain rotational deformations as the crack opens, and aggregate interlock normally remains effective except where yielding of the tensile reinforcement allows widening of the crack.

\subsection{Low Shear Walls}

Category $6(S=1.6)$ shear walls having $h_{\mathrm{W}} / l_{\mathrm{W}}$ ratio less than 1 , detailed for controlled shear behaviour, may be classed as low shear walls. They are true shear walls since, unlike the flexural characteristic of tall cantilever shear walls, the behaviour of low shear walls is dominated by shear effects and consequent diagonal cracking.

The equilibrium of a tall cantilever shear wall element, after formation of a diagonal flexure-shear crack, was considered previously with reference to fig. l. It was shown that since each (idealized) critical diagonal crack intersects the main flexural steel in the tension flange area, vertical reinforcement in the web area is not required for stability of the wall element. In a low shear wall, the situation is very different. Diagonal cracks assumed at $45^{\circ}$ are generally web-shear cracks initiated in the web area by diagonal tensions. Two such cracks, shown in Fig. 3a, extend from the base right through to the top of the wall but do not intersect the vertical flexural steel in the tension flange area. consequently, low shear walls which are loaded by shear forces distributed along their length at the top require both horizontal and vertical web reinforcement distributed uniformly throughout the wall, in order to transfer shear forces and maintain equilibrium of the wall elements.

During controlled shear behaviour, as seismic shear loads increase in intensity numerous diagonal cracks steadily extend and spread more or less evenly to cover the whole wall surface. As the ultimate shear strength of the wall is approached, the distributed web reinforcement controls the opening of diagonal cracks, so that eventually nearly all of the web steel crossing the numerous cracks should reach yield stress. Thus, seismic energy dissipation is expected to be well distributed throughout the entire wall, and premature, localized shear failure avoided.

The extensively cracked shear wall in the condition just described is a highly indeterminate load - resisting system. To make an approximate assessment of forces acting in this system, it is assumed that all distributed web reinforcement carries similar stresses at or near yield and that diagonal cracking is at $45^{\circ}$. Since dominant shear effects generally preclude attainment of theoretical flexural strength, it is further assumed that vertical flexural steel concentrated in the tension flanged area remains at stresses below yield. On this basis, the effects of load transfer on the elements of a diagonally cracked low shear wall may be discussed using the idealized truss representation shown in fig. 4. The simplified version in fig. 5 shows only those forces which appear necessary for equilibrium of the wall elements shown, and these elements are considered in the following paragraphs.

\section{Wall Element 1}

Element 1 of the low shear wall represented in fig. 5 requires horizontal web reinforcement percentage $\mathrm{ph}$ to transfer its shear load $V_{1}$ across both diagonal cracks to element 3 . As indicated by the calculation in fig. 6 , an equal percentage of distributed web steel $\mathrm{p}_{\mathrm{v}}$ crossing the diagonal crack generates the diagonal compression forces at the top of the wall element, and in so doing provides a vertical force equal to $V_{l}$ which resists overturning of element 1. The equilibrating compression force $C$ concentrated at the wall extremity (flange area) reaches its maximum value $\mathrm{C}=$ $\mathrm{V}_{1}$ at the toe of element 1. This compression flange force is preferably resisted by reinforcement sized and detailed to avoid buckling; and the same bars provide an efficient flange tension force $T=V_{l}$ (refer to element $3 a$, fig. 5) when load acts in the reverse direction.

\section{Wall Element 2}

Bounded by two diagonal cracks, element 2 transfers its applied shear $V_{2}$ by diagonal compression (concrete arch action) directly to the base and into the foundation, without assistance from the horizontal web steel passing through element 2, fig. 5. Direct transfer of the shear load requires vertical web reinforcement in the same percentage $p_{V}$ as required for element 1 to provide a vertical force equal to $v_{2}$ to generate the diagonal compression forces and resist overturning. The vertical web reinforcement which provides stabilizing forces in element 1 passes down through element 2 and is anchored in the foundation, but the forces in these bars are not essential to shear transfer or stability of element 2 itself.

\section{Wall Element $3 a$}

The horizontal web reinforcement percentage $\mathrm{p}_{\mathrm{h}}$ apparently transfers the element 1 shear force $V$ from the compression flange area of element $\mathrm{I}$ right through the wall length to the tension flange area of element 3. Vertical flange reinforcement provides a tension force reaching the value $\mathrm{T}=\mathrm{V}_{1}$ at the base reaction, and generates the diagonal compressions. If these tension bars are placed close to the wall extremity (or in the flange if one exists) and they remain at stresses below yield as assumed above, they are effective in distributing the shear $V_{1}$ via the diagonal compressions along the full base length of element 3a. Any horizontal cracking at the base of this element should not be significant or affect transfer of forces at the base. The vertical flange bars are also effectively placed to resist compression flange reaction forces $v_{1}$ when the load acts in the reverse direction (refer to element 1 ).

\section{Wall Element $3 \mathrm{~b}$}

An often-used alternative detail, represented as element $3 \mathrm{~b}$ in figs. 4,5 appears to be disadvantageous and could in 
some cases significantly affect wall behaviour. The practice of spreading the flange tension reinforcement providing a vertical force $V_{1}$ over the full base length of element 3 , in combination with vertical web reinforcement carrying force $v_{1}$ already required (stabilizing element 2 and controlling the diagonal crack), results in vertical steel percentage $2 \times \mathrm{p}_{\mathrm{v}}$ providing a force $2 \times V_{l}$ distributed over the base length $\left(=h_{w}\right)$ of element 3 . In consequence, the concrete diagonal compression forces and also the base reactions (i.e. the base shear $V_{1}$ and vertical compression force equal to $V_{1}$ ) appear to be no longer distributed over the base length of element 3. These resultant forces now act close to the diagonal crack, and at the base a concentrated reaction now exists at the toe of element $3 \mathrm{~b}$ (figs 4,5 ), possibly causing failure by localized compression or bar buckling. It is likely that as ultimate shear strength is approached the vertical steel distributed along element $3 \mathrm{~b}$ will reach yield (unlike element $3 a$ flange steel assumed to remain below yield). resulting extensive horizontal cracking along the base of element $3 b$ confirms the concentration of forces at the toe, with consequent risk of local compression failure as already indicated.

It seems clear from this approximate analysis of low shear walls that the several wall elements behave after cracking more or less separately in a shear mode. Especially in fig. $3 \mathrm{~b}$, the base section resisting moment $M_{R}$ does not correspond to the flexural base resistance of the wall if it were to act as a single unit. Flexural capacity, considering all reinforcement crossing the base section, also has little meaning. Design of the wall reinforcement should therefore use specified load factors and the strength design method, considering diagonal cracking and resulting forces as indicated above.

Test investigation would be of assistance in clarifying the above aspects of low shear wall behaviour. The unfavourable effects of element $3 b$ detailing could have particular application to detailing of reinforced masonry shear walls.

\subsection{Intermediate Shear Walls}

Previous sections have considered tall ductile shear walls $\left(h_{\mathrm{W}} / l_{\mathrm{W}} \geqslant 2\right)$ and low shear walls $\left(h_{\mathrm{W}} / l_{\mathrm{W}}<1\right)$. "Intermediate" shear walls herein refer to square shaped walls and also to walls of intermediate height so that this group covers the range $1 \leqslant h_{\mathrm{w}} / l_{\mathrm{w}} \leqslant 2$. These walls are included within category $6(S=1.6)$, and clause 3.3.4.3 requires that web reinforcement be provided for seismic energy dissipation by controlled shear behaviour. Critical diagonal cracks may occur over the full height of such walls, while in some cases flexural cracking, with yielding of steel in tension, may be significant in design (fig. 2).

Theoretical flexural capacity may not be attained in many intermediate shear walls. In walls with flanges, considerably more reinforcement may be provided in the flange area to meet requirements for resistance in the other horizontal direction. Forces in the flexural reinforcement will remain below yield level and prevent plastic hinging, so that diagonal web cracking and shear resistance will determine wall strength and govern behaviour. Distributed vertical and horizontal web reinforcement should be designed using specified load factors and the strength design method, to resist the full design shear forces at moderate intensities of nominal shear stress (not more than say $0.45 \sqrt{f_{C}^{\prime}} \mathrm{MPa}$, i.e., $5.4 \sqrt{\mathrm{f}_{\mathrm{C}}^{\prime}}$ psi. This level of nominal shear stress should prevent a non-ductile sliding shear failure occurring adjacent to the wall base (this type of failure cannot be prevented by additional stirrup reinforcement).

Other intermediate shear walls (e.g. walls of rectangular section not carrying significant axial loads) may be designed so that flexural yielding of tension reinforcement can occur near the base. Since flexural cracking and diagonal web cracking will both be significant, distributed vertical and horizontal web reinforcement is required as in other cases and is provided by load-factor and strength design methods. The probability of flexural yielding suggests that, additionally, a capacity design approach should be applied within a height equal to $l_{W}$ above the base. This approach could include:

(a) calculation of base moment capacity considering all vertical bars and allowing for overstrength

(b) providing horizontal shear reinforcement within the height $h_{w}$ to resist the full shear force associated with moment capacity, neglecting contribution of concrete to shear resistance

(c) ensuring that flexural capacity is associated with a modest level of nominal shear stress (not more than $0.5 \sqrt{f_{C}^{\prime}} \mathrm{MPa}$, i.e. $6 \sqrt{\mathrm{f}_{\mathrm{C}}^{\prime}} \mathrm{psi}$ to avoid risk of sliding shear failure.

Assuming that all web reinforcement carries stresses close to yield, and using the same idealised truss type representation previously applied to low shear walls, an approximate assessment of the effects of controlled shear behaviour of intermediate shear walls is made in the following paragraphs :

\section{Square-shaped Walls}

In detailing web reinforcement for controlled shear behaviour, an approximately square wall is basically similar to elements 1 and 3 of a low shear wall.

After extensive shear cracking, the wall in fig. $7 \mathrm{a}$ has vertical flange bars resisting forces $T=C=V$ while distributed vertical web bars $P_{\mathrm{V}}$ (Fig. 6) stabilize element 1. Toe compression $\mathrm{C}=\mathrm{V}$ is taken mostly by flange bars. Assuming tension flange bars are at stresses below yield, the base shear will be spread along the base length $l_{\mathrm{w}}$ as indicated in $\mathrm{fig}$. $7 \mathrm{a}$. If tension flange bars yield (commonly the case in square walls of rectangular section) flexural cracking near the base as well as diagonal cracking will be significant, and the base shear will now tend to concentrate at the compression toe of the wall which is already provided with flange bars. 
The wall in fig. $7 \mathrm{~b}$ has flange and web vertical bars distributed over the base length carrying a force $T=2 \mathrm{~V}$. As in the low shear wall element $3 \mathrm{~b}$, these bars are likely to yield across flexural cracks near the base. Reaction forces concentrated at the toe of the wall are now $2 \mathrm{~V}$ vertically and $V$ horizontally and must be carried by the concrete (or masonry) since there is no concentration of vertical bars at the wall ends. Although flexural yielding should be beneficial to seismic performance, the higher reaction forces at the toe may require special confining measures in the case of masonry walls $(6)$.

\section{Walls of Intermediate Height}

In considering controlled shear behaviour and web reinforcement required by the code for walls up to $h_{\mathrm{W}} / 1_{\mathrm{W}}=2$, it is assumed that a critical diagonal crack 1 could form to intersect the main flexural bars at the top corner or even along the top of the wall (fig. 2). Other diagonal cracks at lower levels include crack 2 intersecting the compression zone in the vicinity of the base.

With idealizations as previously, fig. $8 a$ is one representation of a wall not containing vertical web bars. Horizontal web bars of percentage $P_{h}$ transfer the shear force V. Element 1 is stable only if the tension force $T_{1}=V / 2$ at crack $l$ can be reliably developed in the main bars by anchorage in element 1 . Stability of element 2 is similarly dependent upon reliable anchorage of main bars above their intersections with cracks such as crack 2. For walls up to $h_{w} / l_{W}=2$ the code infers that this system does not reliably control diagonal cracking behaviour. Hence, distributed vertical web bars of percentage $\mathrm{P}_{\mathrm{V}}$ equal to the horizontal web reinforcement $P_{h}$ (refer fig. 6) should be provided to stabilize elements such 1,2 and thus control diagonal cracking similarly to low shear walls.

Fig. $8 b$ represents a similar wall containing distributed vertical and horizontal web bars in addition to main flexural steel. At crack 1, it is assumed that the main steel lacks effective anchorage and thus the vertical web steel stabilises element 1. At crack 2, both main and web steel should contribute in varying proportions to stabilise element 2 and control cracking. At the base section of walls where yielding of flexural reinforcement may occur, the possibility of flexural yielding as well as diagonal web cracking suggests that capacity design criteria should be employed within a height equal to $l_{\mathrm{W}}$ above the base. This would require increased horizontal shear reinforcement over that height (i.e. covering element 3 ) as indicated previously (refer to section 3.2 , third paragraph listing points $a, b, c)$.

\section{DUCTILE COUPLED SHEAR WALLS}

Coupled cantilever shear walls designed and detailed for ductile flexural yielding (clause 3.3.4.1 and commentary) comprise category 3 of Table 5 for which a structural type factor $S=0.8$ is specified. This value reflects the commentary note that wellproportioned structures of this type may be the best earthquake-resisting structural systems available in reinforced concrete, their overall behaviour being similar to that of a moment resisting frame but with very significant advantages.

The shear walls - the vertical component members of the system - are subject to clause 3.3.4.2 (ductile cantilever shear walls). Thus, dimensional limitations $\left(h_{W} / I_{W} \geqslant 2, l_{W} \geqslant 1.5\right.$ metres) apply, unless the vertical members are detailed as required for the columns of ductile frames. The coupling beams, interconnecting the shear walls in a rational and reasonably regular manner, should be of substantial capacity to transfer shear forces from one wall to another. The magnitude of shear forces transferred should be sufficient to develop axial forces in the "tension" and "compression" walls or piers to form a stable and reliable system resisting at least two-thirds of the total overturning moment acting on the structure. Reinforced concrete coupling beams will usually require diagonal reinforcement capable of repeatedly yielding in tension and compression reversals.

The code intent is that the coupling system should be designed to function as the major energy-dissipating components, well dispersed over the entire structure, providing several lines of defence during earthquake attack. The designer should aim for full yield capacity to be reached first in all coupling beams, so that early damage occurs in less critical, repairable areas, the gravity load-carrying wall elements receive the greatest degree of protection, and permanent damage (e.g. building misalignment) is delayed. In large earthquakes, seismic loads will further increase after all coupling beams have yielded, causing subsequent yielding to develop at the base of the tension wall. Finally, the maximum resistance of the system will be mobilised when the compression wall base just develops its flexural capacity, the latter being determined largely by the magnitude of the compressive axial force acting in that wall. At the instant when the compression wall base just attains its flexural capacity, the system can be represented as in fig. 14.

The ductile seismic behaviour envisaged in the code reflects the comprehensive research work undertaken at the University of Canterbury by Professor T. Paulay, who has contributed much valuable information and guidance for design $(3,4)$. Paulay's recommendations are incorporated in the capacity design of coupled shear walls with diagonally reinforced coupling beams, which is outlined in the following sections of this paper.

\subsection{Analytical Frame Model}

For a coupled wall system comprising two cantilever shear walls connected by a regular system of relatively deep beams of uniform clear span between wall faces, a conventional frame model is established using centroidal lines of wall sections and mid-depth lines of coupling beams. Member properties for wall piers extend full height between beam intersection points. For the beams, member properties apply over a flexible length taken as the clear span distance (plus concrete cover at 
each wall face to main core reinforcement if desired), beyond which rigid zones extend to intersections of wall lines (fig. 10).

Establish the total reduced gravity load $W_{t}$ (taken as $D+L / 3$ or $1.1 \mathrm{D}$ ) for the building and obtain the code specified lateral load assuming the maximum zone coefficient (i.e. short building period). Making allowance as specified for horizontal torsional moments acting on the building, allocate to the coupled system considered the total code lateral load E (i.e. base shear) to be resisted by the system, and distribute this load over the wall height to each floor level as specified. Part of E should preferably be applied separately to each of the two wall. piers at each load level, proportionately to the wall pier stiffness properties to be assumed for analysis. Establish the contributory gravity floor loads $\mathrm{D}, \mathrm{L}_{\mathrm{R}}$ to be applied at each pier and beam intersection; the selfweight of each wall may be applied uniformly over the height of each wall pier as in fig. 10, or introduced at beam intersections.

Specified code loading combinations include $0.9 \mathrm{D}+\mathrm{E} ; \quad 1.0 \mathrm{D}+1.3 \mathrm{~L}_{\mathrm{R}}+\mathrm{E}$. Assessment of $\bar{w}$ all pier cracked stiffness properties for use in analysis should consider the net axial tension or net axial compression forces on the pier section at any level due to the appropriate gravity load component combined with the overturning component force $\mathrm{T}=\mathrm{C}$ transferred from one wall to the other via the coupling beam shears. Providing stiffness properties approximate to the cracked condition under the combined loads, load cases analysed may be with $\mathrm{E}$ acting separately or in the specified combinations. Lateral load $\mathrm{E}$ and base reactions are shown in fig. 13.

\subsection{Alternative Frame Model}

An alternative analytical frame model has been used for assessing cracked stiffness properties of wall pier sections under combined gravity and code lateral loads, and also for comparative analyses with a corresponding conventional frame model to obtain approximate stiffness coefficients representing cracked wall pier and

diagonally reinforced beam properties (fig. 11). Diagonally reinforced coupling beams are modelled as axially-loaded pin-ended diagonal members attached through horizontal rigid members to intersection points on wall lines as shown.

One disadvantage is that many more members and joints are used in modelling the structure, than for the conventional frame model. However internal moments and axial forces can be obtained more directly and the model is better suited to assessing wall cracking and modifying pier properties in successive analyses. Providing computer capacity is adequate, the model appears suited to analytical studies at the final design stage of major coupled shear wall structures and possibly also for those with some unusual features.

From cracked section studies and analytical comparisons based mainly on a ninestorey coupled shear core structure, J. A. Norton obtained the approximate cracked stiffness coefficients shown in fig. 9. The basis for the properties listed is given in subsequent paragraphs.

\subsection{Coupling Beam Cracked Stiffness Properties}

In applying approximate coefficients to gross concrete beam section properties to represent the reduced beam stiffness after diagonal cracking, the following points are noted (refer to fig. 9):

(a) Significant diagonal cracking occurs in both diagonally reinforced and conventionally reinforced coupling beams at relatively low shear loads (about 20\% of coupling beam ultimate shear load) during the first load applicable, and beam stiffness properties drastically reduce. For design purposes, the reduced stiffness can reasonably be taken as representative of the diagonally cracked beam throughout subsequent behaviour.

(b) For the effect of non-uniform shear stress distribution upon shear deformations: $\alpha=\frac{\text { maximum shear stress }}{\text { mean shear stress }}=1.5$ approx. (1.2.

Allowance is made by taking the web area of the gross concrete section $A_{w e b}$ acting to resist shear deformations and reducing this area by the factor $2 / 3$ to obtain the uncracked shear area $A_{s h}$, thus:

$A_{\text {sh }}=\frac{2}{3} A_{\text {web }}$

(c) To obtain properties after diagonal cracking, the coefficient applied to corresponding uncracked section properties (based on the gross concrete section) may be taken as :

for diagonally reinforced coupling beams: 0.33 for conventionally reinforced coupling beams :

(d) The coefficient in (c) applies to both flexural and shear deformations. Thus, for diagonally reinforced beams ( $\mathrm{Ig}=\mathrm{I}$ of the gross concrete section):

$I_{z}$ (diagonally cracked) $=0.33 \mathrm{Ig}$

$A_{y}($ diagonally cracked $)=0.33 A_{\text {sh }}=0.33$

$$
=0.33\left(\frac{2}{3} A_{\text {web }}\right)
$$

(e) The slab diaphragm resists axial deformation of the coupling beams. The corresponding cross-sectional beam area $A_{X}$ is increased beyond the beam gross concrete area to a suitably large number to represent the effect of beam and slab.

\subsection{Wall Pier Cracked Stiffness Properties}

Flexural cracking reduces wall pier properties, especially for the "tension" wall, and significantly changes the relative proportions of moment and shear carried by the tension and compression walls. Changes in wall pier properties for the lower 2 or 3 stories have a greater effect on the analysis than similar changes at higher levels. The following points arise (refer to fig. 9):

(a) Using a reinforced concrete cross-section 
analysis computer programme for a particular L-shaped wall cross-section and reinforcement pattern (having a total vertical reinforcement percentage $\left.P_{t}=1.27 \%\right), J$. A. Norton developed the curves shown in fig. 12 relating flexural parameter I and axial deformation area $\mathrm{A}$ of the cracked section to the ratio $M / P$.

(b) The diagrams of fig. 12 suggest that for similar rectangular and L-shaped walls and reinforcement, cracked I value is unlikely to exceed approximately 0.3 I gross for any section subject to a tension axial force.

(c) Where a net axial tension exists, axial deformations will be extensions. Across cracks, axial tension will be resisted effectively by steel area only (modular ratio $\mathrm{n} x$ total area $A_{S}$ of vertical bars in the section), while assistance from concrete between cracks will reduce the total extension of the pier. Thus, for piers of the tension wall where a net axial tension exists or is expected (e.g. in lower 2-3 stories of a wall over 6 stories high), the axial deformation wall area $A_{x}$ may be taken as:

$A_{x}=2 x\left(n \cdot A_{s}\right)$

(d) Shear deformations of wall piers should preferably be included if possible. However, caution is advised here. It is particularly recommended that the shear parameter $A_{y}$ be taken as the uncracked value for both tension and compression piers of any storey, i.e.:

$A_{y}=A_{\text {sh }}$ (uncracked) $=\frac{2}{3} A_{w e b}$

This is because widely varying concrete compression areas due to flexural cracking do not cause similar variations in shear stiffness areas; and unsoundly based relative differences in pier shear stiffness may introduce serious error into the analysis.

\subsection{Total Base Resistance and Gravity Load Transfer}

Under the action of specified combinations of gravity loads and code lateral load E, the conventional frame model using suitable cracked section member properties is analysed to give the reaction components at the wall base shown in fig. 13 .

The sum of all coupling beam shear forces $\Sigma V$ develops axial forces in each wall of value $\mathrm{T}=\mathrm{C}=\Sigma \mathrm{V}$ at the base, also representing the amount of gravity load transferred from the tension wall to the compression wall via the coupling system.

The applied external overturning moment, due to resultant code lateral load $E$ acting at height $h_{E}$ above the wall base is $M_{E}=E \times h_{E}$. The total resistance at the wall base to the external moment $M_{E}$ is provided by three components: tension wall base moment $\mathrm{M}_{1}$; compression wall base moment $\mathrm{M}_{2}$ : and the wall axial force component $\mathrm{T}$ (from coupling beam shears $\sum V$ ) acting at lever arm $\ell$ :

$\mathrm{M}_{1}+\mathrm{M}_{2}+\mathrm{T} \cdot l=\mathrm{M}_{E}$

4.6 Checks : Deflection, Period, Beam Shear Stress
From the analysis results for specified combinations of gravity loads and code lateral load, several checks may be made as follows:

(a) Maximum interstorey drift: Obtain the maximum interstorey deflection from the analysis, and increase by the modification factor $v$ (refer to code cl.3.10.1). Compare with code limits, cl. 3.10.3. Consider proposed detailing of non-structural members, which are required to be separated where interstorey deflection exceeds 0.0006 of the storey height.

(b) Building period: Obtain the top deflection from the analysis and using this value calculate the top deflection $\triangle$ corresponding to the set of horizontal loads given in the code, cl. 3.2.3. Hence calculate the building period. Consider whether any revision of code loads and analysis is necessary.

(c) Maximum shear stress in coupling beams: Obtain the shear forces in the coupling beams and calculate nominal shear stresses. For diagonally reinforced coupling beams, upper limits are not as well defined (nor apparently as critical) as for shear stresses in conventionally reinforced beams. However, consideration of desirable maximum shear stress of $0.85 \sqrt{f_{C}^{\prime}} \mathrm{MPa}$ ( $\left.10 \sqrt{f_{C}^{\prime}} \mathrm{psi}\right)$ at hinging overstrength beam capacity with diagonal reinforcement suggests that shear stresses from code load analysis should preferably not exceed about $0.65 \sqrt{\mathrm{f}_{\mathrm{C}}^{\dagger}} \mathrm{MPa}$ (7.8 $\sqrt{f_{C}^{i}}$ psi).

\subsection{Coupling Beam Design}

Consider suitable diagonal bar arrangements, geometry and detailing. Design each coupling beam individually to select actual, final bar sizes and numbers ensuring that steel areas provided are no greater than necessary for code loading analysis and other requirements. Calculate required steel areas using normal methods $(\phi=0.9$; specified minimum $f_{\mathrm{y}}=275 \mathrm{MPa}$ ).

Avoidance of unnecessary overstrength in the coupling beams is of key importance to coupled shear wall performance and sequence of hinge formation. Otherwise, hinging of overstrength beams may be delayed so that hinging occurs prematurely at the tension wall base. Considerable overstrength is also inherent in normal methods used for calculating steel areas required. Possible design measures to minimize inherent overstrength, resulting in some reduction in actual steel areas provided, are referred to in appendix I.

\subsection{Coupling Beam Overstrength Capacities}

From the diagonal reinforcing bar sizes and numbers actually detailed for the coupling beams, calculate overstrength capacities allowing for all foreseeable sources of overstrength (use $\phi=1.0$, steel stress $350 \mathrm{MPa}$ for grade 275 bars - refer to appendix I).

Sum the beam overstrength capacity shears for all coupling beams to obtain the maximum value Tmax of the wall axial force component acting on the wall base section at lever arm $l$ to resist part of the external overturning moment. Tmax is 
also the maximum amount of gravity load which can be transferred from the tension wall to the compression wall via the coupling system at hinging capacity, and this should be considered when investigating foundation loads and the need to avoid premature rocking of the foundation.

\subsection{Wall Base Vertical Steel Design}

Design of vertical wall reinforcement at the base is governed mainly by conditions at the base of the tension wall. Here, the net axial force on the wall section for design is taken as $(0.9 \mathrm{D}$ gravity force Tmax), i.e. the net force acting when all coupling beams reach capacity. From the code loading analysis, the tension wall base moment $\mathrm{M}_{1}$ and the overturning axial force component $T$ (from beam shears at code loading) are obtained. Design criteria for the tension wall base are not yet well established. The writer recommends two conditions:

(a) With net axial force (0.9D gravity - Tmax) acting, design for moment $M_{1}$ using appropriate $\phi$ value and specified minimum $\mathrm{f}_{\mathrm{y}}(=275 \mathrm{MPa})$.

(b) With net axial force (0.9D gravity-Tmax) acting, design for a proportionately increased moment $\left(M_{1} \times \operatorname{Tmax} / \mathrm{T}\right)$ assumed to act at the tension wall base when the coupling system reaches overstrength hinging capacity. Since capacity conditions are envisaged, use $\phi=1.0$, with specified $\mathrm{f}_{\mathrm{y}}(=275 \mathrm{MPa})$. This design provides a section with "nominal, ideal strength" to resist the assumed axial load and moment. In specially difficult design situations the writer would consider providing a section having "probable strength" to resist the above load and moment; this requires less steel area since $\phi .=1.0$ is used with "probable" steel strength $300 \mathrm{MPa}(\doteqdot 1.1 \mathrm{fy})$. (Refer to listed flexural strengtis in Appendix I).

Design of vertical steel at the tension wall base is accomplished by selection of trial wall reinforcement arrangement and construction of the interaction diagram for moment and axial load. As for ductile cantilever shear walls, for ductility and efficiency reasons nearly all the main vertical bars should be positioned close to the extremities of the wall section or in the flange, with only minimum (0.25\%) vertical steel in the web area or as necessary for other reasons.

However, the area of main vertical reinforcement placed in the wall extremity close to the openings and coupling system should be minimised as far as possible (while remaining sufficient to resist reversed pier moment in the event of failure of the coupling system). These bars adjacent to the openings are in compression when resisting moment in the tension wall, and since similar reinforcement is usually detailed for the compression wall the same bars when in tension will also determine overstrength moment capacity of the compression pier under the axial force acting. Excessive compression pier capacity requires heavy horizontal shear reinforcement in both wall piers, especially in the base hinge region. For this reason, the importance of minimising vertical bars adjacent to the wall opening should be kept in view when selecting trial arrangements for design of the tension wall base described above.
In some cases, e.g. low coupled walls, similar design criteria to (a), (b), above should be applied to the vertical steel at the compression wall base for moments $\mathrm{M}_{2}$, $\left(M_{2} \times \frac{T \max }{T}\right)$, as a check for adequacy.

\subsection{Wall Base Overstrength Capacity}

The detailed arrangement of vertical reinforcement for both tension and compression wall base sections is now known. The maximum overturning component of axial force at the wall base sections, Tmax, was obtained previously. The specified gravity load $\left(1.0 \mathrm{D}+1.3 \mathrm{~L}_{\mathrm{R}}\right)$ is now assumed to act to provide wall section axial force components in combination with \pm Tmax. Interaction diagrams for the wall base sections are drawn for overstrength capacity conditions $(\phi=1.0$ and e.g. $350 \mathrm{MPa})$, giving wall base capacity moments $\mathrm{M}_{1}$ and $\mathrm{M}_{2} \mathrm{O}$ for the assumed axial forces ( $\left.1.0 \mathrm{D}+1.3 \mathrm{~L}_{\mathrm{R}} \pm \mathrm{Tmax}\right)$.

Thus, the maximum total overstrength capacity at the wall base section, i.e. maximum resistance of the system, is obtained:

$M_{\max }=M_{1}^{\circ}+M_{2}^{\circ}+T_{\text {max }} \cdot l$

The maximum overcapacity factor $\gamma$ of the coupled wall system as designed is assessed as the ratio of the maximum resistance $M_{\max }$ to the external moment $M_{F}$ due to code

lateral load $\mathrm{E}$ resisted by the base section: $\gamma=\frac{M \max }{M_{E}}=\frac{M_{1}{ }^{\circ}+M_{2}^{0}+T_{\max \cdot \ell}}{M_{1}+M_{2}+T \cdot \ell}$

\subsection{Wall Base Shear Design}

Ductile behaviour of the coupled shear wall system as designed requires the provision of horizontal shear reinforcement in the wall piers to prevent non-ductile shear failure when the maximum total overstrength capacity of the system is reached. Especially in the tension wall, the shear force transmitted to the base is limited to the shear which by laws of mechanics can exist in the pier when its hinge capacity moments are developed. By comparing the hinge capacities $M_{1}, M_{2}{ }^{\circ}$ it is seen that tension pier shears are limited but consistent with $\mathrm{M}_{2}$ o very large shear forces may develop in the compression wall pier at the base.

Similarly to the system overcapacity factor $\gamma$, a member overcapacity factor for the compression wall pier at the base is denoted by $\alpha_{2}$. This factor is applied to the compression pier shear $V_{2}$ obtained from the code lateral load analysis to obtain the compression pier hinge capacity shear force $\mathrm{V}_{2}$ o for design:

$\mathrm{v}_{2}{ }^{\circ}=\frac{\mathrm{M}_{2}{ }^{\circ}}{\mathrm{M}_{2}} \times \mathrm{v}_{2}=\alpha_{2} \cdot \mathrm{v}_{2}$

The large shear forces at capacity in the compression wall coexist with a large axial compression force which determines the moment capacity. Hence in this case the concrete in compression is effective in resisting part of the large capacity shear force (e.g. as permitted by the 1971 ACI Code, clause 11.4). Horizontal shear reinforcement is detailed for the remaining shear force in the compression wall pier. 
Similar horizontal shear reinforcement is provided in both walls. In a similar manner the tension pier hinge capacity shear force $v_{1}{ }^{\circ}$ is obtained:

$\mathrm{v}_{1}{ }^{\circ}=\frac{\mathrm{M}_{1}{ }^{\mathrm{O}}}{\mathrm{M}_{1}} \times \mathrm{v}_{1}=\alpha_{1} \cdot \mathrm{v}_{1}$

The horizontal shear steel already provided should be checked to ensure that the shear $\mathrm{V} O \mathrm{C}$ can be resisted entirely by the reinforcement.

The wall capacity shears $\mathrm{V}_{1}{ }^{\circ}, \mathrm{V}_{2}{ }^{\circ}$ correspond to hinging capacity of the system assuming a (triangular) code load distribution pattern as in the lateral load analysis. For the shear design of major ductile coupled shear wall structures, it should be noted that the increased shear forces caused by dynamic response in higher modes (refer to ductile cantilever shear walls, section 2.3) may apply also to these structures.

\subsection{Wall Reinforcement Design}

A procedure similar to that for the design of vertical reinforcement at the tension wall base may be applied at each level up the building to establish vertical steel requirements at all wall levels above the hinging zone at the base. The interaction diagrams should be used also to check adequacy of vertical steel in the compression wall where necessary.

For the design of shear reinforcement at any level, moment capacity obtained from the interaction diagrams allows the member overcapacity factor a to be assessed at that level. Calculated values of a may be considerably greater than at the base, and at higher levels where hinging is unlikely the values of $\alpha$ adopted for shear design need not be greater than say 2.0 times the corresponding value at the wall base.

Additionally, the analytical technique described in the next section can be used to assess the distribution of moments and shears in the tension and compression walls when the system has reached its total overstrength capacity. Wall shear forces so obtained may need to be increased to allow for dynamic load distributions with height other than the code pattern assumed in the analysis. The analytical results may need to be treated with caution if used for design.

\subsection{Wall Moments and Shears at Capacity}

By means of an analytical frame model with cracked member stiffnesses, subject to gravity loads and code lateral load $\mathrm{E}$ assumed distributed over the wall height as specified, successive analyses can be made under increasing magnitude of lateral load but using a similar load distribution over the wall height.

Plastic hinges where applicable can be modelled by introducing a member end hinge and applying the calculated overstrength capacity moment and shear as external loads at the hinge. The hinge at the tension wall base can be modelled in a similar manner. Some adjustments to cracked member properties may be desirable to allow for reduced stiffnesses at higher loads. Using this technique, successive formation of plastic hinges can be observed as the lateral load increases. Alternatively, the study may omit intermediate stages and consider only the final condition at total capacity of the system.

At the maximum lateral load, corresponding to total overstrength capacity of the system, all coupling beam hinges and that at the tension wall base are modelled. The compression wall base is still considered as cracked elastic and will just reach its overstrength capacity moment $\mathrm{M}_{2}{ }^{\circ}$ (fig. 14). In this condition, the analysis gives an assessment of the distribution of moments and shears in the walls when the system has reached its maximum capacity. However, shear forces so obtained may need to be increased for use in design (refer to the previous section). Since little use has been made of this technique as yet, its reliability is uncertain and caution is advised in applying the results for design of wall reinforcement.

\section{CONCLUSION}

Shear walls coming within categories 3,4 and 5,6 of Table 5 of the New Zealand Loadings Code(1) are required to be designed and detailed to dissipate seismic energy in the manner envisaged by that code. This requires a basic understanding of seismic resistance when walls are in the fully cracked condition, with reinforcement at or near yield where applicable.

Seismic behaviour, cracking and capacity of coupled shear walls (category 3 ) have been comprehensively researched $(3,4)$. The resulting confidence in the ductility of well-proportioned coupled shear walls is reflected in code requirements. This paper outlines the application of capacity design principles to these structures. Similar methods are also outlined for tall, ductile cantilever shear walls (categories 4, 5) which at flexural capacity are similar to ordinary cantilever members.

Fully cracked conditions in category 6 shear walls are less predictable and are not so well understood. The paper attempts to assess the likely force systems on wall elements existing after extensive diagonal cracking (assumed at $45^{\circ}$ ). The distributed vertical and horizontal web reinforcement which appears necessary for reliable seismic performance in such shear-dominant structures is discussed. Test investigation would be of considerable assistance in establishing design and detailing requirements for these walls.

Nothwithstanding the need for test clarification of the post-cracking condition and reinforcement requirements for category 6 shear walls, the paper indicates reinforcement design principles for these, and also for the ductile cantilever and coupled shear wall structures which in the present state of knowledge should ensure satisfactory seismic energy dissipation in the manner envisaged by the loadings code.

\section{ACKNOWLEDGEMENTS}

The author wishes to thank Mr. O. A. Glogau, Chief Structural Engineer, Ministry of Works and Development, for his continued encouragement and guidance. Grateful 
acknowledgement is made to $\mathrm{Mr}$. J. A. Norton, who performed numerous studies and analyses, to Mr. R. L. Williams, and to other Ministry of Works and Development engineers for contributions on capacity design. The design approach described in section 4 of the paper follows that used for public buildings under Mr. Glogau's direction, except that the author has included his own suggestions where detailed criteria are not well established yet. Discussions with $\mathrm{Mr}$. K. E. Williamson are appreciated.

The permission of Mr. N. C. McLeod, Commissioner of Works, to present this paper is acknowledged.

\section{REFERENCES}

1. NZS 4203:1976: Code of Practice for General Structural Design and Design Loadings for Buildings. Standards Association of New Zealand.

2. ACI 318-71: Building Code Requirements for Reinforced Concrete (ACI 318-71). American Concrete Institute.

3. Paulay, T.: "Design Aspects of Shear Walls for Seismic Areas". Civil Engineering Research Report No. 74-11. University of Canterbury, October 1974.

4. Paulav, T.: "Some Aspects of Shear Wall Design". Bulletin of the New Zealand National Society for Earthquake Engineering, Vol. 5, No. 3 September 1972 .

5. Blakeley, R. W. G., Cooney, R. C. and Megget, L. M.: "Seismic Shear Loading at Flexural Capacity in Cantilever Wall Structures". Bulletin of the New Zealand National Society for Earthquake Engineering, Vol. 8, No. 4 December, 1975.

6. Priestley, M. J. N. and Bridgeman, D. O. "Seismic Resistance of Brick Masonry Walls". Bulletin of the New Zealand National Society for Earthquake Engineering, Vol. 7, No. 4, December 1974.

7. R. P. Park and T. Paulay, "Reinforced Concrete Structures". 1975.

\section{APPENDIX I : FLEXURAL STRENGTHS AND CAPACITY}

In developing specific criteria for use in capacity design, Park and Paulay(7) have listed four distinct levels of theoretical flexural strength applicable to a reinforced concrete section subject to inelastic curvatures due to yielding of the tension steel:

\section{(1) Dependable strength}

Nominal, ideal strength (as in (2) below) multiplied by the appropriate capacity reduction factor, $\phi$. It is the lower bound of member flexural strength.

(2) Nominal, ideal strength

Theoretical flexural strength of the section calculated by accepted principles using specified minimum steel and concrete strengths. $(\phi=1.0$.

\section{(3) Probable strength}

Theoretical flexural strength of the section calculated using expected mean material strengths. $(\phi=1.0$.$) For grade$ 275 reinforcing bars the value $300 \mathrm{MPa}$ $(\risingdotseq 1.1 \mathrm{fy})$ appears suitable.

(4) Overstrength capacity

The expected maximum moment capacity of a section, making full allowance for all sources of overstrength including:

(a) actual reinforcing bars detailed, including slab reinforcement;

(b) actual yield strength taken at upper limit levels:

(c) strain hardening. $(\phi=1.0$.

This can be considered as the upper bound of member flexural strength. For grade 275 bars, a value not less than $350 \mathrm{MPa}$ ( $1.27 \mathrm{fy}$, or $16.7 \%$ over "probable" $300 \mathrm{MPa}$ strength) is suggested as an interim measure (see next paragraph).

Full allowance for overstrength is essential to capacity design of ductile structures if non-ductile failure is to be avoided. Limited existing bar strength data indicate upper limit (95\%) values from $330 \mathrm{MPa}\left(1.20 \mathrm{f}_{\mathrm{y}}, 48 \mathrm{ksi}\right.$ ) to $345 \mathrm{MPa}$ (1.25 $\left.\mathrm{f}_{\mathrm{y}}, 50 \mathrm{ksi}\right)$. Recently, full-size bar specimens tested in the as-rolled condition commenced strain-hardening at less than 10 times yield strain for grade 275 bars. Significant strength increase at plastic hinges can thus be expected due to this effect. The writer therefore suggests a bar stress value not less than $350 \mathrm{MPa}$ as above for calculating overstrength capacity.

While full allowance for overstrength is essential, the bar stress level used for calculating required steel areas resisting earthquake loading combinations does not appear so critical to performance. Minimisation of overstrength is of key importance where, as in coupling beam design, overstrength may detrimentally alter the sequence of hinge formation causing premature wall hinging. One possible design measure to minimise overstrength is to consider "probable" bar strength $300 \mathrm{MPa}$, and not specified minimum $275 \mathrm{MPa}$, when calculating diagonal steel areas for coupling beam design. Alternatively, the possible use of $\mathrm{f}_{\mathrm{y}}=275 \mathrm{MPa}$ together with a capacity reduction factor $\phi=1.0$ would achieve a similar reduction in overstrength. Both measures result in some reduction in actual steel areas which otherwise would be provided in the coupling beams.

\section{APPENDIX II : ADDITIONAL DETAILING ASPECTS}

Detailing considerations for shear walls designed for seismic resistance, additional to those referred to in the paper itself, are outlined in the following notes.

\section{Diagonally Reinforced Coupling Beams}

1. Compression forces are carried across wide open cracks (opened by previous tension reversal) almost entirely by diagonal bars yielding in compression. To prevent buckling of individual bars after spalling of cover concrete, each set of diagonal bars should be located within a cage of ties or rectangular spiral spaced at not more than four times the diagonal bar diameter(3) nor more than $100 \mathrm{~mm}$ (fig. 15).

2. To prevent lateral buckling of the caged diagonal member as a whole at right angles to the plane of the beam, four diagonal bars are normally detailed at the corners of the cage of confined concrete. 
These bars should be widely spaced in the buckling direction (beam thickness direction) for maximum flexural strength and rigidity. The two cages should mesh together at the midspan crossing point so that the tension diagonal laterally supports the compression member at this point.

3. Where wall thickness is only $250 \mathrm{~mm}$ (the practical minimum), each set of diagonal bars may be located in a line near the middle of the wall thickness. Maximum lateral cage dimension is then obtained by detailing four smaller size keeper bars at the cage corners, so that sufficient flexural strength is provided to resist buckling of the cage member. To prevent unwanted contribution to diagonal member axial strength, keeper bars may be turned at the midspan crossing point to anchor in the other diagonal member (fig. 15).

4. Generous anchorage length for diagonal bars in the wall is essential. Paulay(3) recommends $50 \%$ increase above normal anchorage length for individual bars, together possibly with splaying of bars within the wall to better disperse anchorage forces. So that full interaction of forces within the wall/ beam joint area can develop, anchoring diagonal bars should cross a sufficient area of intersecting horizontal wall bars to ensure full transfer of tension forces into the horizontal wall bars.

5. Diagonal bars preferably should not be turned into the horizontal direction after entering the wall since high induced forces may develop at the bend. If a bend is unavoidable, this should be positioned within a suitably confined wall core area.

6. Basketing reinforcement comprises nominal vertical stirrups and top, bottom and intermediate nominal horizontal bars in each beam. This reinforcement is detailed for crack control and to support beam concrete other than that within the diagonal caged members.

Shear Wall Elements

7. In cantilever shear walls, the effect of diagonal cracking is to vertically displace the moment diagram by up to two stories. For this reason main flexural bars should be extended to a level sufficiently higher than theoretically required before being terminated. Similarly, calculated shear reinforcement should be detailed at levels 1-2 stories higher than the level at which it is theoretically required, and also confining reinforcement should extend higher than otherwise required. A similar effect may occur in coupled shear walls.

8. The hinging region may extend for a height equal to the horizontal length of the wall. Over this height above the wall base, or at other possible hinge locations, lapping of main vertical bars should not be permitted.

9. Over considerable heights of shear walls, and also especially in coupled walls subject to significant tensions at capacity, main vertical bars may be stressed to high levels or beyond yield. Lapping of shear wall vertical bars should therefore be approached with caution. For D28 and larger bars, and possibly also for D24 bars in some cases, connection should be by full strength butt weld or equivalent mechanical connection.

10. Wall horizontal shear reinforcement is detailed outside the main vertical bars. Especially in yielding area, cover concrete may become ineffective, causing failure at lap splices. In these areas, D24 bars and larger should be spliced by full strength butt weld or equivalent. Horizontal sheer bars should anchor adequately at the wall extremities, e.g. by bending round to enclose main flexural bars. Mechanical anchorage by site fillet-welding bars projecting through anchor plates (plus additional bar end extension, $9 \mathrm{~mm}$ minimum beyond the weld) also provides site tolerance on length of longer horizontal bars.

11. The detailing of cross-ties or of deformed bar hairpins is recommended in lower stories where wall yielding may occur. These ties resist buckling of main vertical bars yielding in compression, and they also assist confinement of concrete and prevent splitting along the middle-line of thicker walls (Fig. 15). 


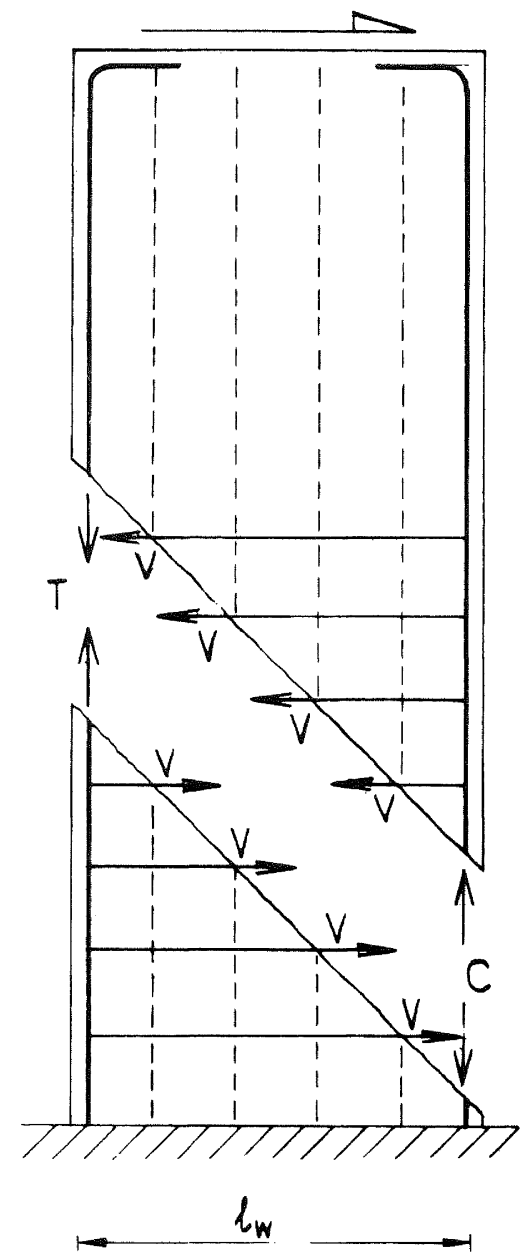

TALL, DUCTILE CANTILEVER SHEAR WALL: $\frac{h_{w}}{l_{w}} \geqslant 2$

FIGURE 1

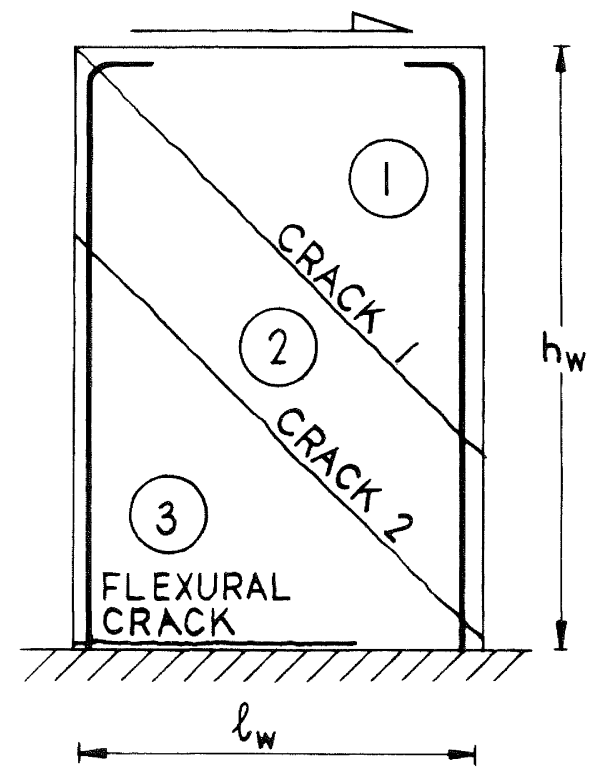

CANTILEVER SHEAR WALL:

$1<\frac{h_{w}}{l_{w}} \leqslant 2$

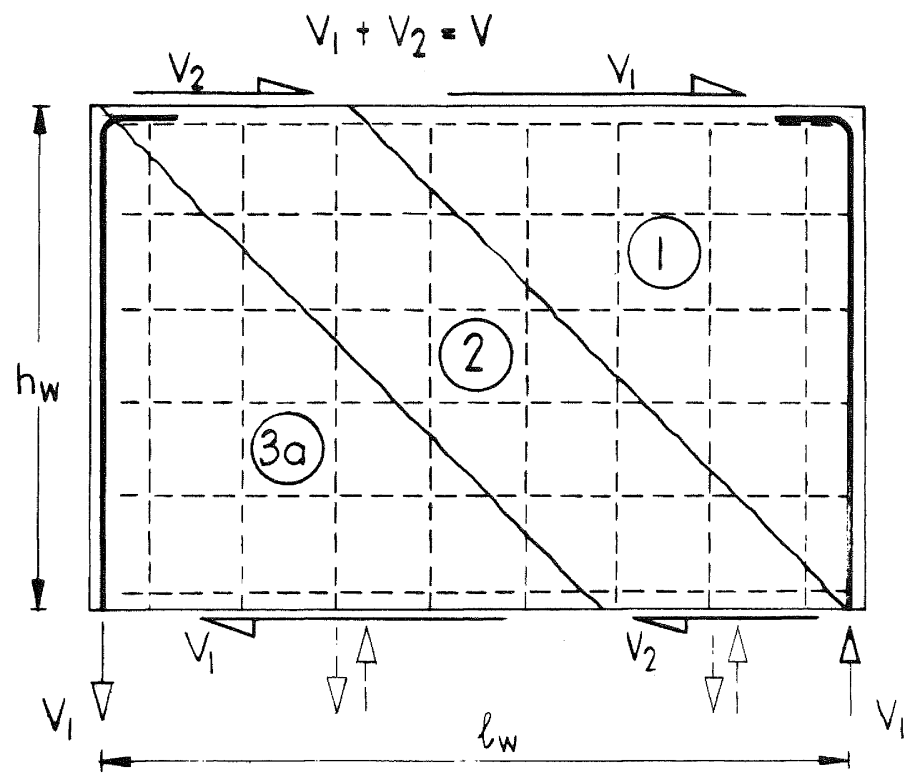

$M_{R}=V_{1} l_{W}=V \frac{h_{W}}{l_{W}} \cdot l_{W}=V h_{W}=M_{E}$

LOW SHEAR WALL. VERTICAL STEEL

IN FLANGE AREAS AND WEB:

$$
\frac{h_{W}}{l_{W}}<1
$$

\section{FIGURE 3a}

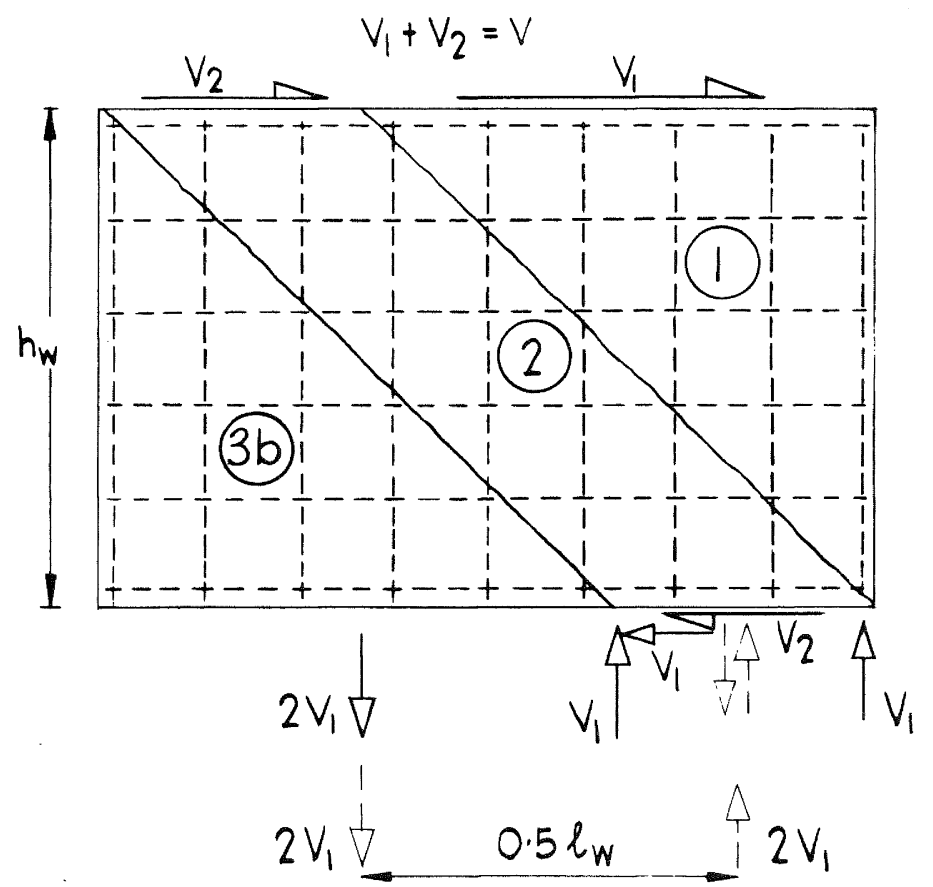

$M_{R}=V_{1} \frac{h_{W}}{2}+V_{1}\left(l_{w}-\frac{h_{W}}{2}\right)=V_{1} \ell_{w}=V h_{W}=M_{E}$ LOW SHEAR WALL. VERTICAL STEEL DISTRIBUTED OVER BASE LENGTH:

$$
\frac{h_{W}}{l_{W}}<1
$$

FIGURE $3 b$ 

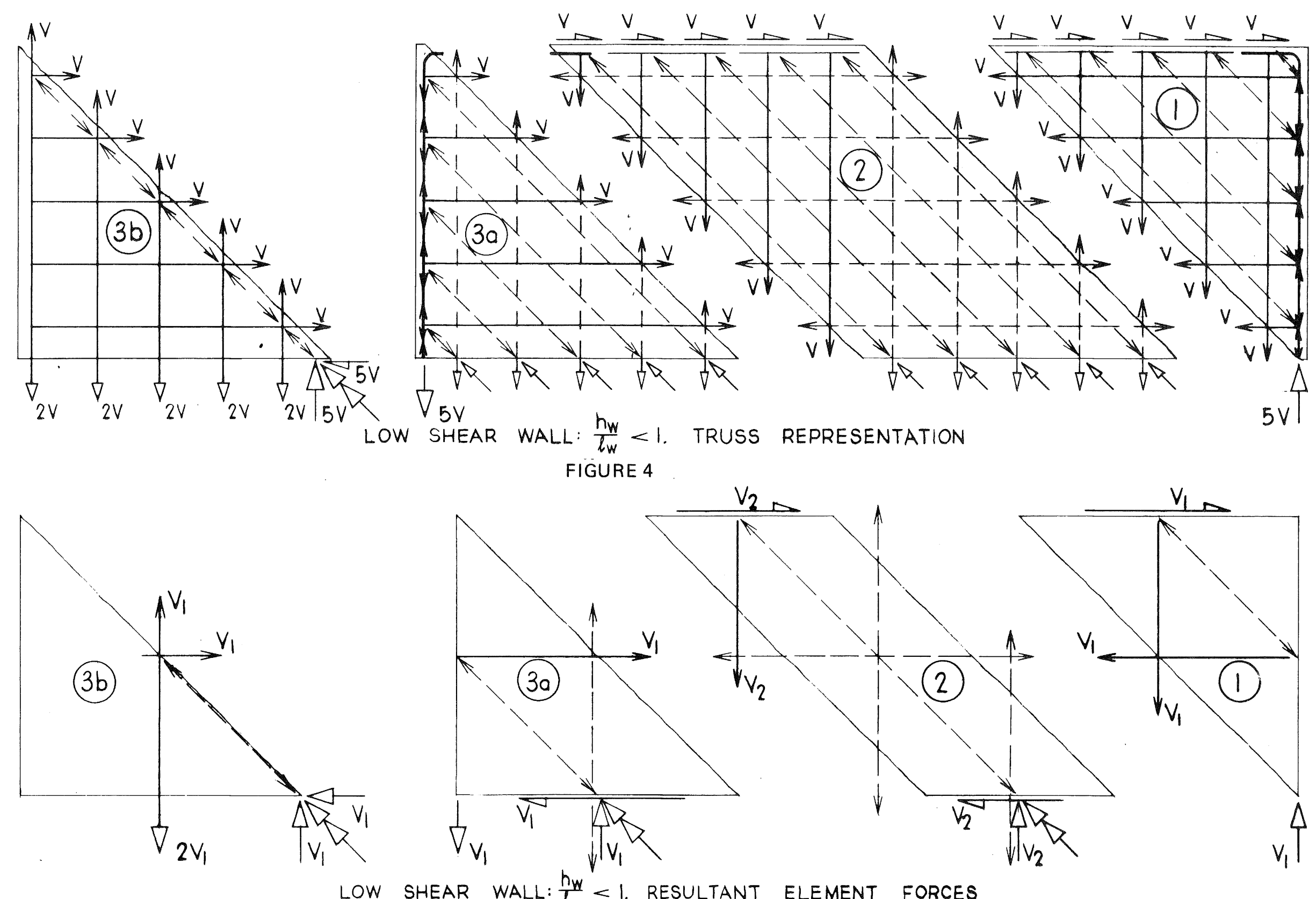

LOW SHEAR WALL: $\frac{h_{w}}{l_{w}}<1$. RESULTANT ELEMENT FORCES 


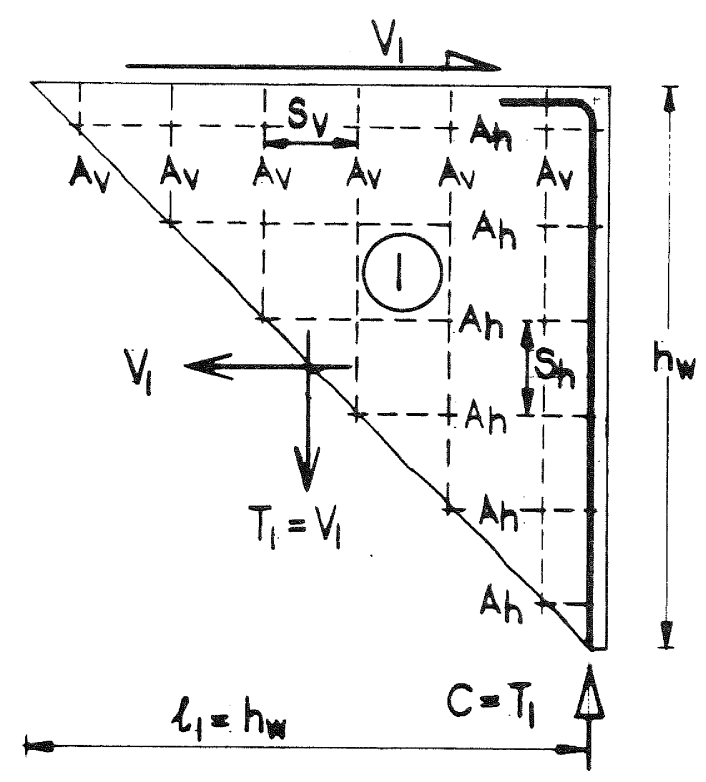

EQUILIBRIUM OF ELEMENT

$$
\begin{aligned}
& V_{1}=\frac{h_{w}}{l_{w}} \cdot V=f_{y} \cdot A_{h} \cdot \frac{h_{w}}{S_{h}} \\
& T_{1}=f_{y} \cdot A_{v} \cdot \frac{l_{1}}{S_{v}}=V_{1} \\
& \therefore \frac{V_{1}}{b \cdot h_{w}}=\frac{A_{h}}{b \cdot S_{h}} \cdot f_{y}=\frac{A_{v}}{b \cdot S_{v}} \cdot f_{y} \\
& \text { ie } v=P_{h} \cdot f_{y}=P_{v} \cdot f_{y} \ldots \ldots . . \\
& \text { and } P_{h}=P_{v} \ldots \ldots \ldots . . .
\end{aligned}
$$

WEB STEEL PERCENTAGE $P$ FOR CRACK CONTROL FIGURE 6
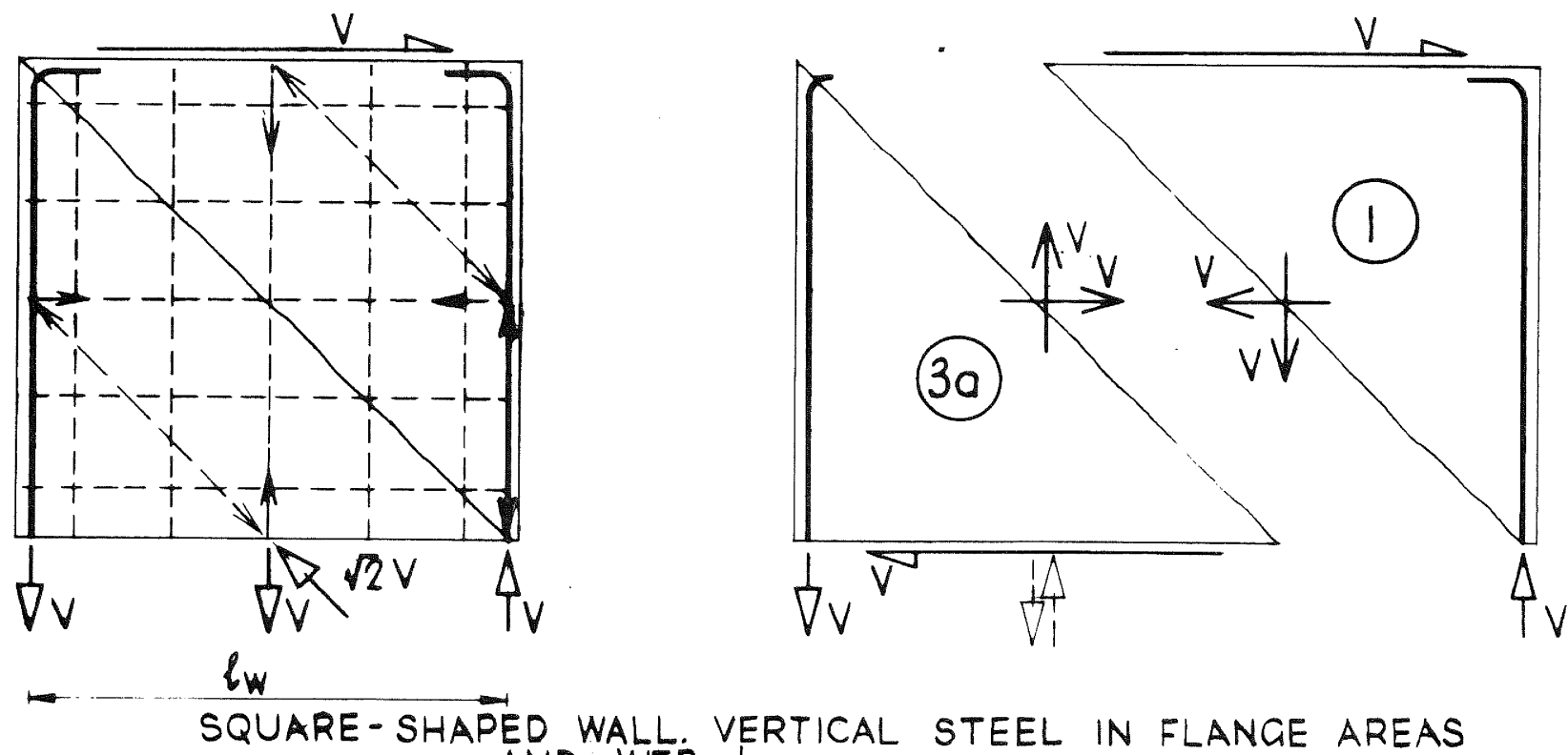

AED WALL. VERTICAL STEEL IN FLANGE AREAS AND WEB : $\frac{h_{w}}{l_{w}}=1$

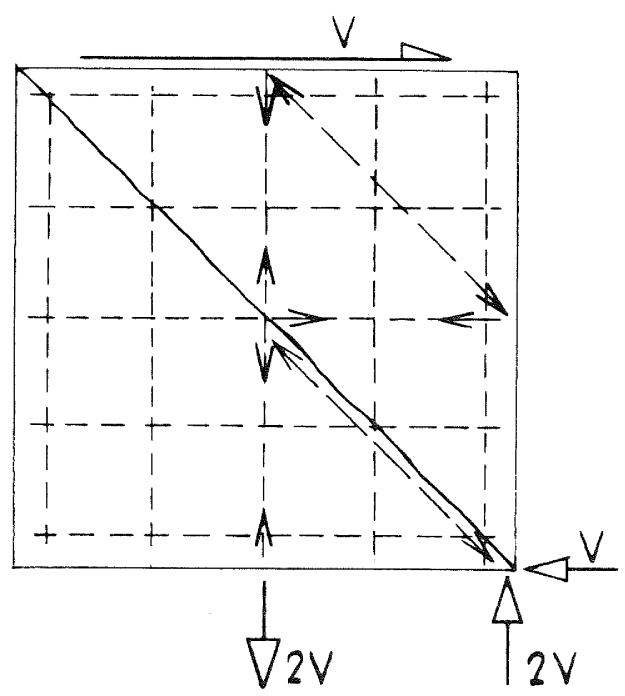

FIGURE 7a

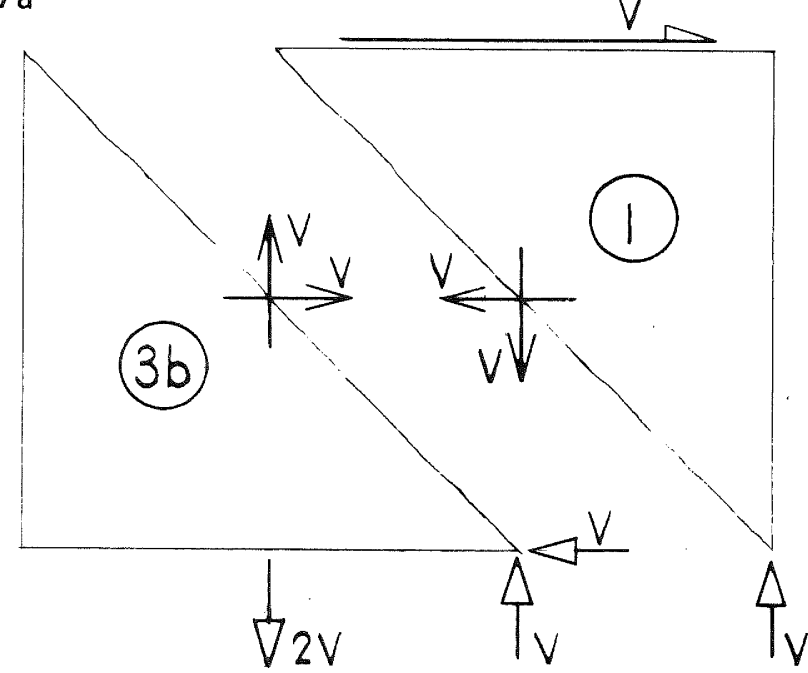

SQUARE-SHAPED WALL. VERTICAL STEEL DISTRIBUTED

OVER BASE LENGTH: $\frac{h_{w}}{l_{w}}=1$ 

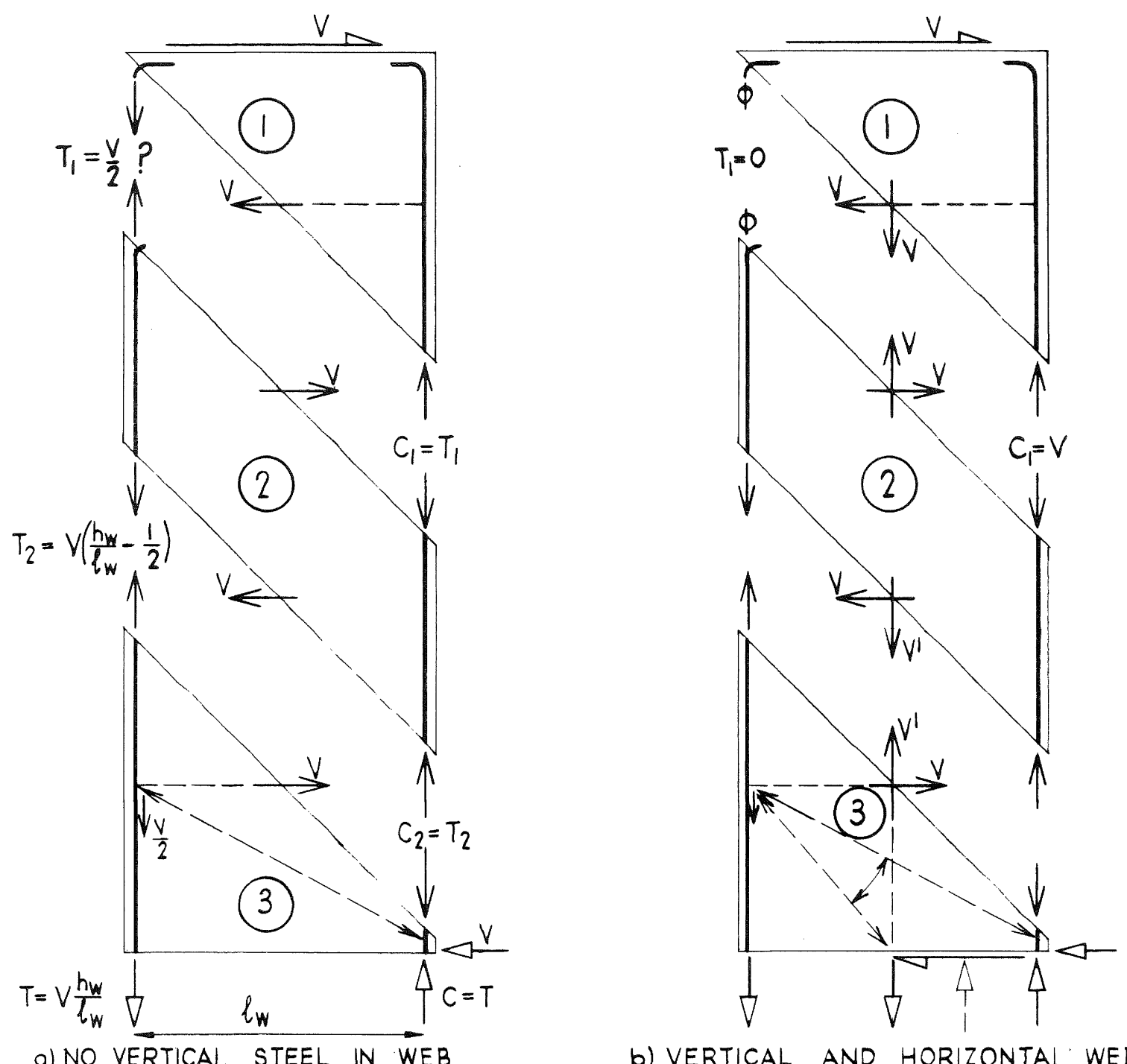

b) VERTICAL AND HORIZONTAL WEB STEEL CANTILEVER SHEAR WALL: $1<_{l_{w}}^{h_{w}} \leqslant 2$

FIGURE 8

\begin{tabular}{|c|c|c|c|}
\hline & $\begin{array}{c}\text { FLEXURAL DEFORMATION } \\
\text { PARAMETER } \\
I_{z}\end{array}$ & $\begin{array}{c}\text { SHEAR DEFORMATION } \\
\text { PARAMETER } \\
\text { AY }\end{array}$ & $\begin{array}{c}\text { AXIAL DEFORMATION } \\
\text { PARAMETER } \\
A_{x}\end{array}$ \\
\hline $\begin{array}{l}\text { DIAGONALLY REINFORCED } \\
\text { COUPLING BEAM }\end{array}$ & 0.33 I gross & $\begin{array}{c}0.33 A_{\text {sh }} \\
\left(A_{\text {sh }} \div \frac{2}{3} A_{\text {web }}\right)\end{array}$ & $\begin{array}{l}\text { A gross for beam } \\
\text { and floor slab } \\
\text { (Large value) }\end{array}$ \\
\hline $\begin{array}{l}\text { TENSION WALL: } \\
\text { UPPER STORIES }\end{array}$ & 0.3 Igross & $\frac{2}{3} A_{\text {web }}$ & 0.7 Agross \\
\hline $\begin{array}{l}\text { LOWER 2-3 STORIES } \\
\text { (If net axial tension } \\
\text { acts on section. }\end{array}$ & $0.3 I_{\text {gross }}$ & $\frac{2}{3} A_{\text {web }}$ & 2.n. $A_{s t .}$ \\
\hline $\begin{array}{l}\text { COMPRESSION WALL } \\
\text { UPPER STORIES } \\
\text { BASE STOREY ONLY }\end{array}$ & $\begin{array}{l}1.0 \text { I gross } \\
0.8 \text { I gross }\end{array}$ & $\begin{array}{l}\frac{2}{3} A_{\text {web }} \\
\frac{2}{3} A_{\text {web }}\end{array}$ & $\begin{array}{l}1.0 \text { Agross } \\
0.9 \text { Agross }\end{array}$ \\
\hline \multicolumn{4}{|c|}{$\begin{aligned} A_{\text {St. }} & =\text { TOTAL STEEL AREA IN THE WALL CROSS-SECTION } \\
n & =\text { MODULAR RATIO }(\doteqdot 10)\end{aligned}$} \\
\hline
\end{tabular}




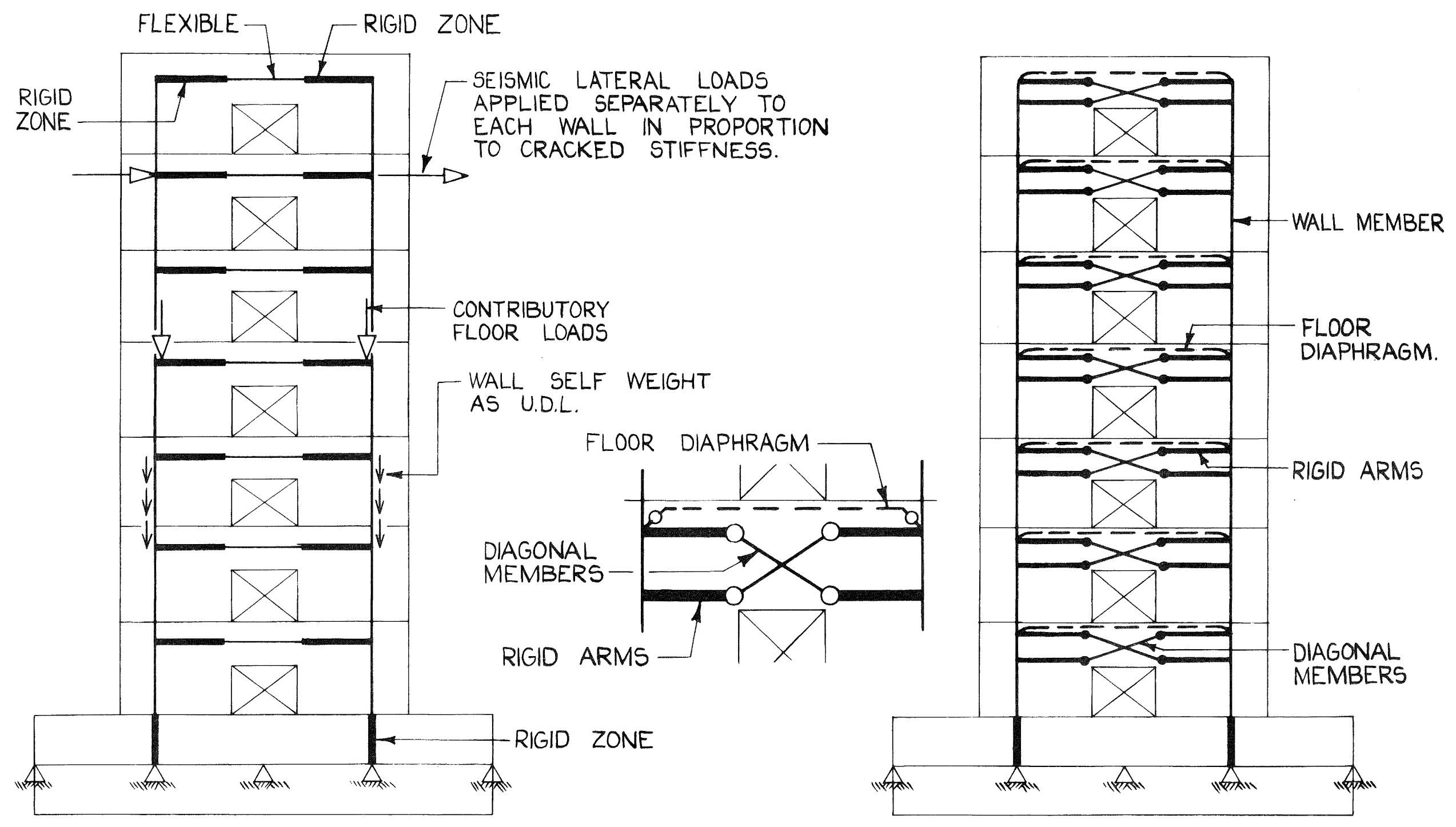

FIGURE 10: ANALYTICAL FRAME MODEL SHOWING TYPES OF APPLIED LOADS

FIGURE 11: ALTERNATIVE FRAME MODEL WITH DIAGONALLY REINFORCED BEAM MODEL 
NOTES: I. CURVES FROM ULTIMATE STRAIN SECTION ANALYSIS FOR A GIVEN CROSS-SECTION AND REINFORCEMENT: $: p_{t}=1.27 \%, I_{\text {gross }}=900 \mathrm{ft}^{4}$, A gross $=40 \mathrm{ft}^{2}$

2. FOR AXIAL TENSION $A_{C R}=2 n . A_{S}$.

3. $I_{C R}, A_{C R}-$ CRACKED TRANSFORMED SECTION VALUES.

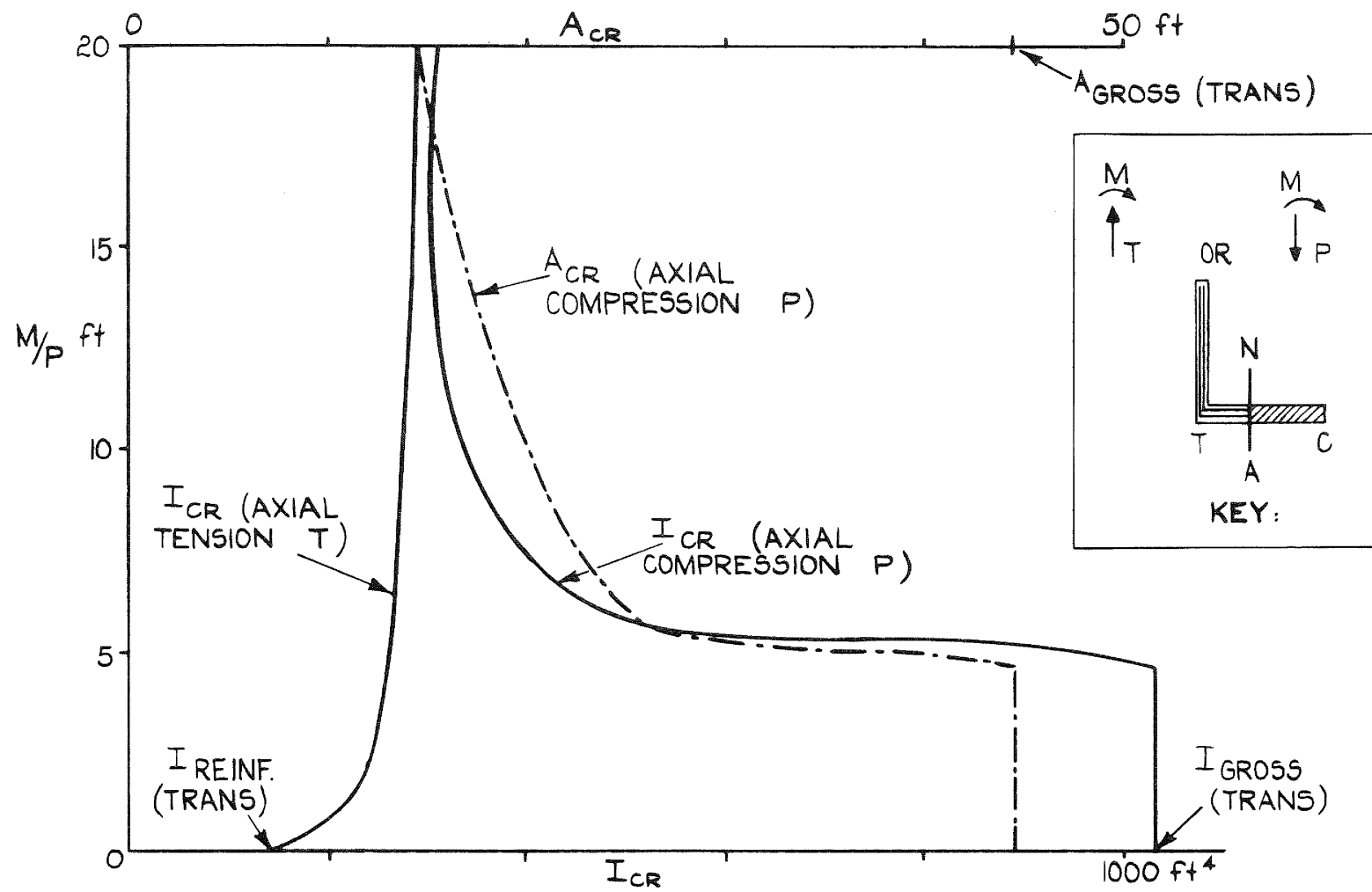

FIGURE 12a: COMPRESSION FIBRE IN THE WEB

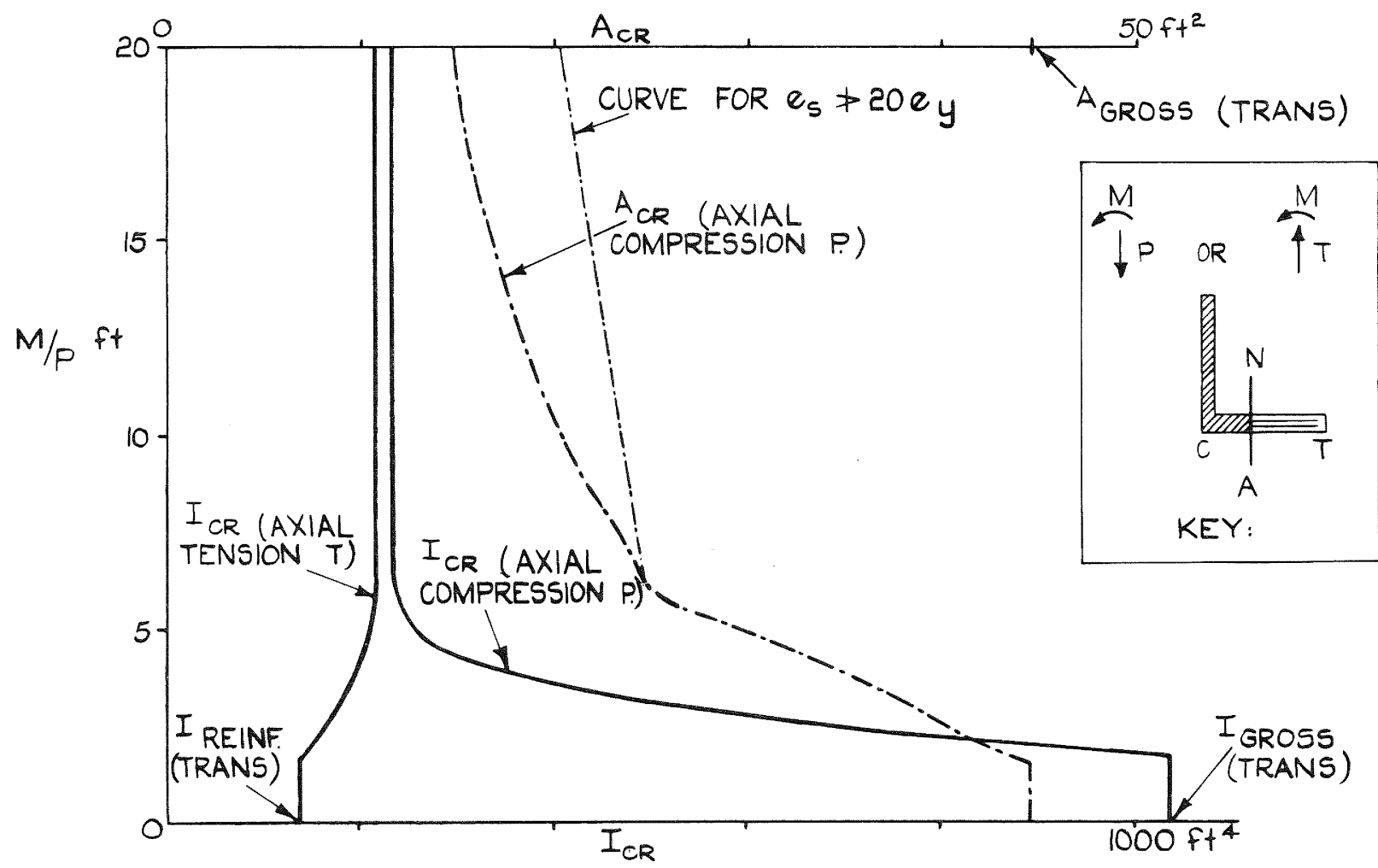

FIGURE 12b: COMPRESSION FIBRE IN THE FLANGE 


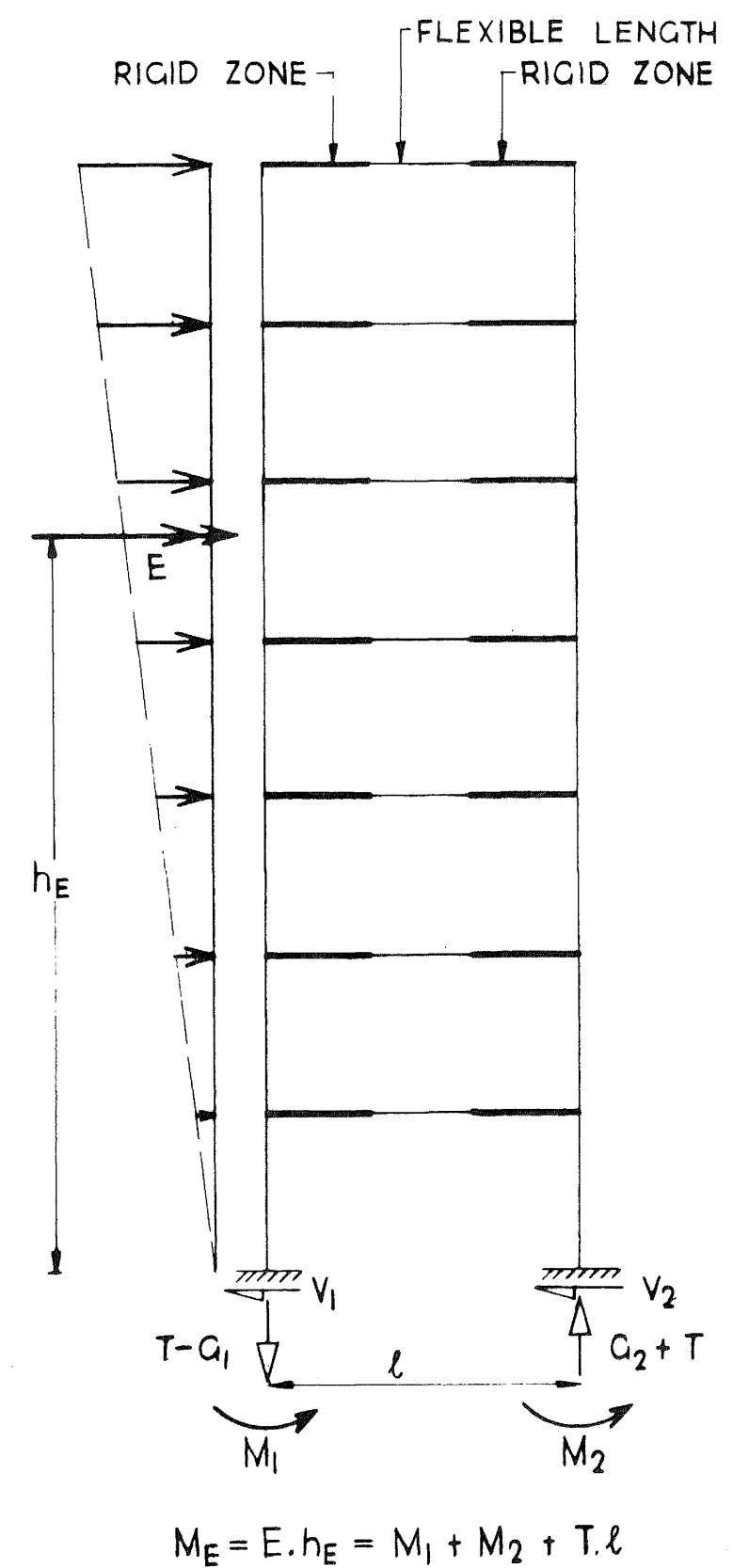

TOTAL RESISTANCE AT CODE LOAD IFIGURE 13

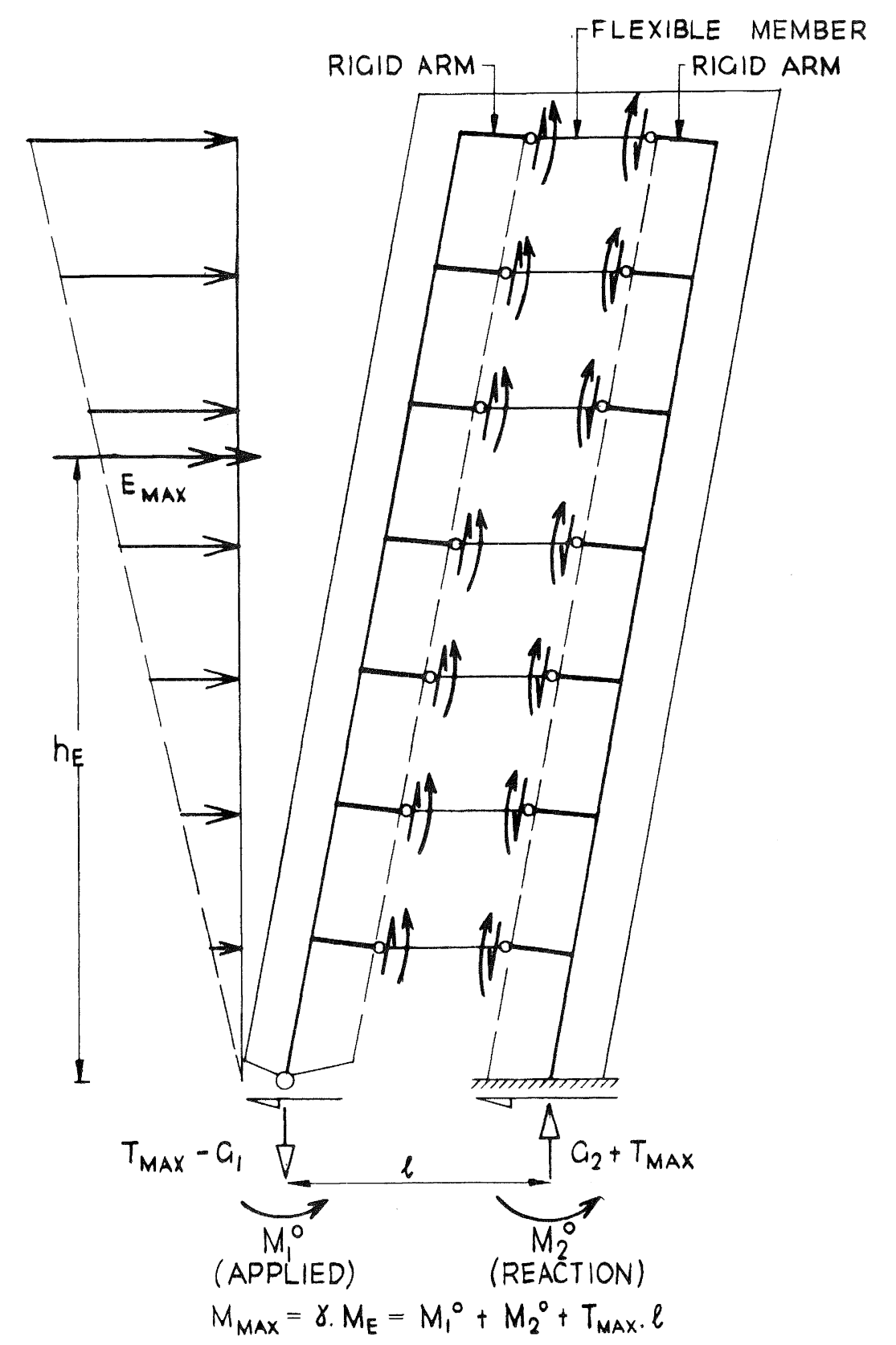

\section{NOTES}

I. $E=$ CODE LATERAL LOAD RESULTANT.

2. $E_{\text {max }}=\gamma \cdot E$

$=$ MAX. LATERAL LOAD (CODE DISTRIBUTION) AT FULL OVERSTRENGTH CAPACITY MMAX OF SYSTEM

3. APPLIED GRAVITY LOADS NOT SHOWN: $C_{1}=G_{1}+a_{2}$ $=\left\{\begin{array}{l}0.9 D \text { OR } \\ 1.00+1.31\end{array}\right.$

4. BEAM OVERSTRENGTH CAPACITY MOMENTS

AND SHEARS APPLIED AND SHEARS APPLIED
AT HINGES AS SHOWN.

5. $M_{1}^{\circ}=$ OVERSTRENGTH CAPACITY MOMENT (APPLIED AT BASE HINGE).

6. $\mathrm{M}_{2}^{\circ}=$ OVERSTRENGTH CAPACITY MOMENT (JUST ATTAINED AT ELASTIC WALL BASE).

MAXIMUM OVERSTRENGTH CAPACITY FIGURE 14 


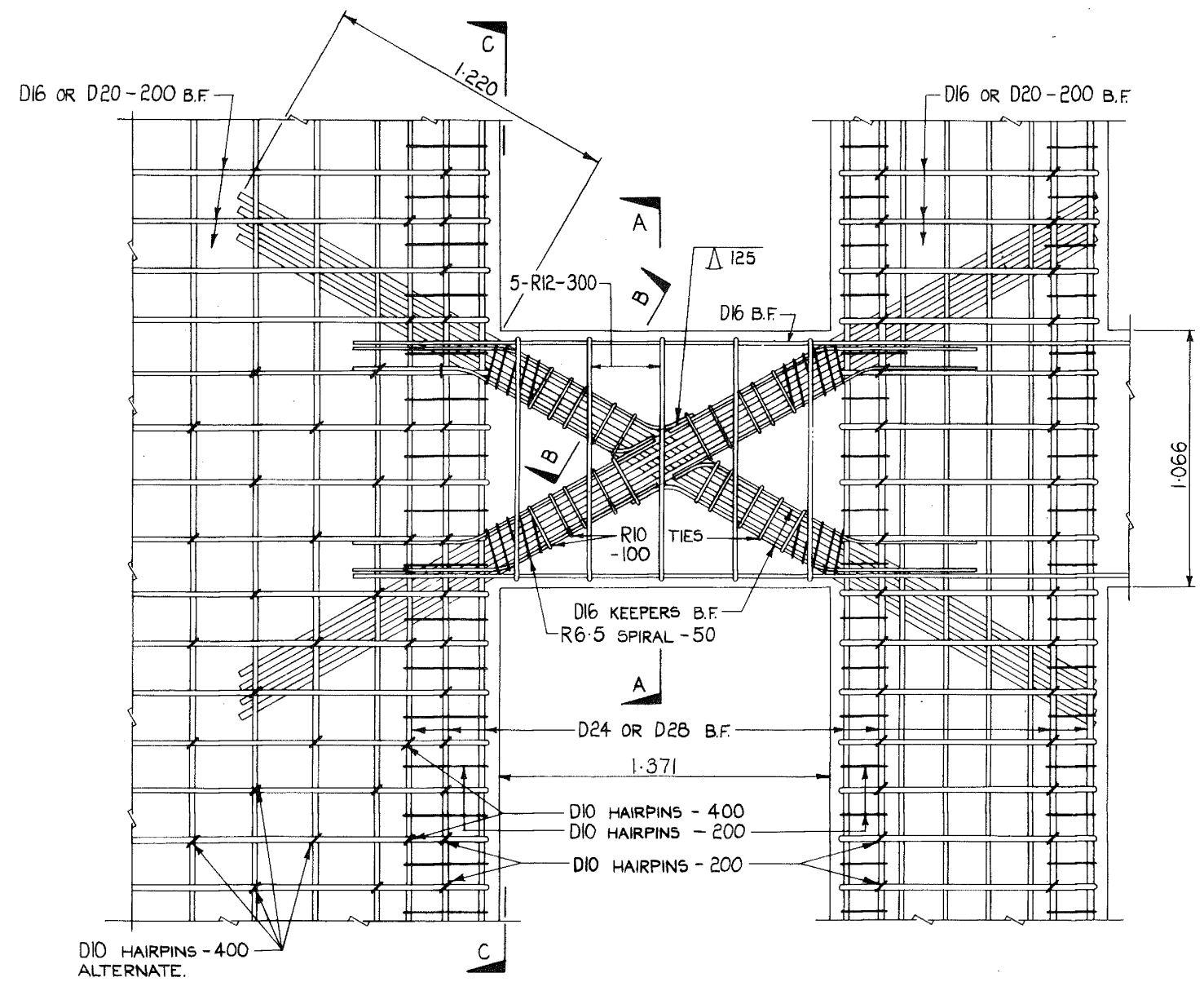

FIGURE 15 : COUPLING BEAM DETAIL FOR $250 \mathrm{~mm}$ WALL
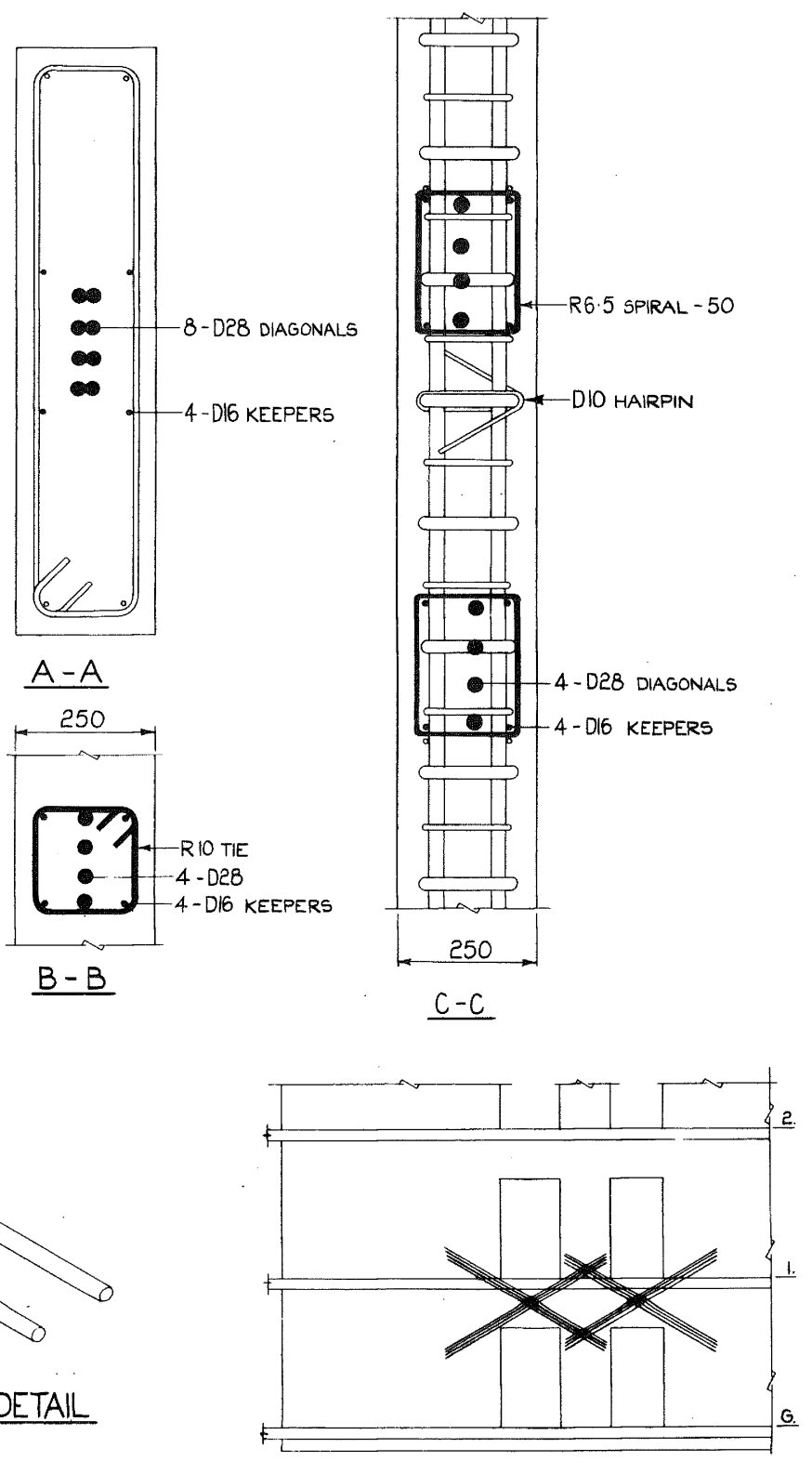